\title{
Using Consolidated Framework for Implementation Research to investigate facilitators and barriers of implementing alcohol screening and brief intervention among primary care health professionals: a systematic review
}

Paul Shing-fong Chan ${ }^{1}$, Yuan Fang ${ }^{2}$, Martin Chi-sang Wong ${ }^{1}$, Junjie Huang ${ }^{1}$, Zixin Wang ${ }^{1,3,4^{*}+}$ and Eng Kiong Yeoh ${ }^{1,3+}$

\begin{abstract}
Background: Alcohol screening and brief intervention (SBI) is recommended to be implemented in primary care settings to intervene against hazardous/harmful drinking. However, studies showed that the uptake rate was low in many regions/countries. This systematic review presented current findings on the facilitators and barriers of SBI implemented by health professionals in primary care settings using the Consolidated Framework for Implementation Research (CFIR)

Methods: We included qualitative, quantitative, and mixed-method studies identified through four electronic databases (PubMed, MEDLINE, Psyclnfo, and Web of Science) from inception to June 2020. Included articles had to address barriers and facilitators of SBI implementation and provide sufficient details that the CFIR domains could be identified and data were abstracted using a standardized extraction form.

Results: A total of 74 studies published from 1985 to 2019 were finally analysed and summarized. The most common facilitators were knowledge and positive beliefs about SBI (characteristics of the individuals) and available resources (inner setting). In contrast, the most common barriers were cost related to implementing SBI (intervention characteristics), negative beliefs about SBI (characteristics of the individuals), and lack of self-efficacy in implementing SBI (characteristics of the individuals). It could be observed that factors related to the inner setting and characteristics of individuals were extensively studied whilst the process received the least attention.

Conclusions: Most of the facilitators and barriers are modifiable. Additionally, most literature focused on various kinds of available assets to implement SBI. To promote the spread of SBI implementation, more high-quality studies on the implementation process are needed. This systematic review could serve as a reference framework for health authorities to devise strategies for improving the implementation of SBI in primary care settings.
\end{abstract}

Trial registration: This systematic review was registered in PROSPERO (CRD42021258833).

\footnotetext{
*Correspondence: wangzx@cuhk.edu.hk

${ }^{\dagger}$ Zixin Wang and Eng Kiong Yeoh contributed equally to this work.

${ }^{4}$ Room 508, School of Public Health, Prince of Wales Hospital, Shatin, N.T. Hong Kong, China
}

Full list of author information is available at the end of the article

(c) The Author(s) 2021. Open Access This article is licensed under a Creative Commons Attribution 4.0 International License, which permits use, sharing, adaptation, distribution and reproduction in any medium or format, as long as you give appropriate credit to the original author(s) and the source, provide a link to the Creative Commons licence, and indicate if changes were made. The images or other third party material in this article are included in the article's Creative Commons licence, unless indicated otherwise in a credit line to the material. If material is not included in the article's Creative Commons licence and your intended use is not permitted by statutory regulation or exceeds the permitted use, you will need to obtain permission directly from the copyright holder. To view a copy of this licence, visit http://creativecommons.org/licenses/by/4.0/. The Creative Commons Public Domain Dedication waiver (http://creativeco mmons.org/publicdomain/zero/1.0/) applies to the data made available in this article, unless otherwise stated in a credit line to the data. 
Keywords: Consolidated Framework for Implementation Research, Alcohol screening, Brief intervention, Facilitators, Barriers, Primary care, Health professionals

\section{Contributions to the literature}

- There is a lack of using implementation frameworks to investigate facilitators or barriers to implementing SBI in previous studies. The Consolidated Framework for Implementation Research was used as a systematic tool to analyse and summarize the data in this review.

- This review provides the most up-to-date synthesis of findings of existing studies about facilitators or barriers of SBI implemented by health professionals in primary care settings.

- This systematic review serves as a reference framework for health authorities to devise strategies for improving the implementation of SBI in primary care settings.

\section{Introduction}

Harmful use of alcohol is a known risk factor for more than 200 types of diseases and injuries [1]. In light of this, alcohol screening and brief intervention (SBI) techniques have been developed in a bid to rectify the situation that excessive alcohol use causes harm. SBI measures a person's level of alcohol consumption and provides brief interventions based on their drinking level [2].

The World Health Organization (WHO) stressed the need to increase coverage of SBI in order to enable early identification and intervention against hazardous/harmful drinking behaviour before serious consequences happen [3]. Across countries, primary care professionals are in a unique and privileged position to identify and intervene against hazardous/harmful drinking $[4,5]$. A meta-analysis of 34 randomized controlled trials (RCTs) showed that stand-alone SBI in primary care settings had a significant and moderate effect in reducing alcohol consumption among hazardous/harmful drinkers, as compared to no or minimum intervention [6]. Early identification and secondary prevention of alcohol use disorder using SBI in primary care settings are strongly recommended by the WHO [2] and other national health authorities [7-9].

However, there was a significant gap between the actual implementation and what is recommended for SBI [10]. Screening rates in European countries were low [11] and less than half of individuals engaged in hazardous drinking were identified by their general practitioners (GPs) [12]. In view of this low uptake of SBI, a number of studies have identified facilitators or barriers to practising SBI in primary care settings. The enabling factors include training [13, 14], proven efficacy of SBI $[15,16]$, financial incentives $[17,18]$, and support from government policy $[15,19]$. On the other hand, a broad variety of barriers were reported, such as lack of time $[20,21]$, lack of counselling skills [16, 22], low availability of screening or intervention tools [23, 24], and fear of harming their relationship with the patient $[25,26]$. Nevertheless, the previous studies did not use an implementation science lens to look at facilitators and barriers to implementing SBI, except for one study. That study used Greenhalgh's conceptual framework for dissemination of innovations to explore facilitators and barriers of SBI implemented by different health professionals in the USA [27].

To our knowledge, two systematic reviews published in 2011 and 2017 summarized the facilitators and barriers to implementing SBI in various settings (e.g. trauma centres, in-patient settings, primary care settings, etc.) $[28,29]$. They did not give a separate discussion on primary care settings where SBI was suggested to be implemented by the WHO. The number of studies conducted in primary care settings was relatively small in the two reviews $(n=31, n=14)$. One of them only included qualitative studies. Furthermore, both systematic reviews did not use the lens of implementation science to synthesize or discuss the findings. The present systematic review included quantitative, qualitative, and mixed-method studies which focused exclusively on primary care settings. It also used an implementation science framework to synthesize the findings.

Due to the lack of application of implementation science framework in this research area, in the present systematic review, the Consolidated Framework for Implementation Research (CFIR) was used to analyse and summarize the facilitators and barriers to implementing SBI in primary care settings. The CFIR has been used to guide the systematic assessment of multi-level implementation contexts to identify facilitators and barriers that might influence implementation $[30,31]$. It provides a comprehensive and standardized list of implementation-related constructs that can be applied across the spectrum of implementation research [30, 31]. The CFIR consists of five domains, including intervention characteristics (features of an intervention that might influence implementation), inner setting (features of the organization that might influence implementation), outer setting (features of 
external context or environment that might influence implementation), characteristics of individuals (individuals involved in implementation that might influence implementation), and implementation process (refers to the plan of implementing a given innovation, to the contents and quality of the plan and how it has been adhered to during the actual implementation process). Making use of the CFIR is helpful to generalize the findings across contexts [30].

The present systematic review included quantitative, qualitative, and mixed-method studies which focused exclusively on facilitators and barriers to implementing SBI in primary care settings. It also used the implementation science framework, the CFIR, to synthesize the findings in a systematic manner, which could serve as a reference framework for health authorities to devise strategies to improve the implementation of SBI in primary care settings.

\section{Methods}

This systematic review was conducted according to a preregistered protocol in PROSPERO (CRD42021258833) and the PRISMA guideline [32].

\section{Search strategy}

Articles were identified by searching the electronic databases PubMed, MEDLINE, PsycInfo, and Web of Science, covering the publication periods from inception to June 2020. Implementing SBI in primary care settings started in the 1980s as a result of the WHO international collaborative project on SBI [33]. The guideline/recommendation and practice of SBI in primary care settings have not changed significantly since then. The Boolean operator was used in the search strategy conducted, using "OR" and/or "AND" to link search terms. The asterisk "*:" was used as a wildcard symbol appended at the end of the terms to search for variations of those terms (Additional file 1).

\section{Selection criteria}

The articles included in this review were original, quantitative, qualitative, or mixed-method studies published in peer-reviewed journals. The studies examined the facilitators and/or barriers of alcohol screening or alcohol brief intervention implemented by healthcare professionals (physicians, nurses, and other health workers) in primary care settings. In this review, barriers refer to obstacles that hinder health professionals from performing SBI and facilitators refer to enabling factors for health professionals to perform SBI. We excluded articles that focused on: (1) efficacy of alcohol screening and brief intervention; and (2) alcohol screening combined with other drugs' screening.

\section{Quality assessment and analysis}

The information from the included articles was assessed by the Mixed-Method Appraisal Tool (MMAT) version 2011 with detailed descriptions of the rating [34]. A data extraction form was used which included reference ID, first author, publication year, title, country, study design, participants, sample size, facilitators, barriers, CFIR domains, and constructs. We used a thematic approach that the facilitators and barriers were coded on the CFIR framework. A six-step data synthesis process of the facilitators and barriers was developed: (1) Two reviewers extracted facilitators and barriers from each article independently; (2) After extraction, they discussed to achieve a consensus on the facilitators and barriers identified in each article. In some cases, wordings of the same facilitator or barrier were slightly different in different studies. The wordings were revised and the same description for the same facilitator or barrier was used after discussion by the two reviewers; (3) Each facilitator or barrier was coded under the domains/constructs of the CFIR by the two reviewers independently; (4) After finishing the coding independently, they discussed the results, and any discrepancies were resolved through discussion; (5) The revised coding results were read and checked by the two reviewers independently to ensure all facilitators and barriers were mapped to the CFIR constructs correctly; (6) All information in the codebook was adapted to make Tables 1 and 2 .

\section{Results}

\section{Identification of studies}

The initial search returned 4078 citations, of which 1285 were excluded due to duplicates (Fig. 1). After that, we further removed 2681 articles after screening for titles and abstracts. We performed full-text screening on 112 articles, of which 38 articles were excluded because they did not meet the selection criteria. Figure 1 presents the PRISMA flow chart of the selected studies.

\section{Overview of included studies}

A total of 74 studies published from 1985 to 2019 were finally analysed and summarized (Table 1) [13-26, 3593]. Most of the studies were performed in Europe $(n=$ $45,61 \%)$, followed by North America $(n=14,19 \%)$, the Asia-Pacific region $(n=7,9 \%)$, South Africa $(n=3,4 \%)$, South America $(n=1,1 \%)$, and different continents $(n$ $=4,5 \%$ ). These studies consist of 49 quantitative studies, 22 qualitative studies, and three mixed-method studies. Among these studies, 51 included physicians only (total sample size: 23597), 5 included nurses only (total sample size: 279), 9 included both physicians and nurses (3918 physicians and 3564 nurses), and 9 included different health professionals (total sample size: 3694). Regarding 


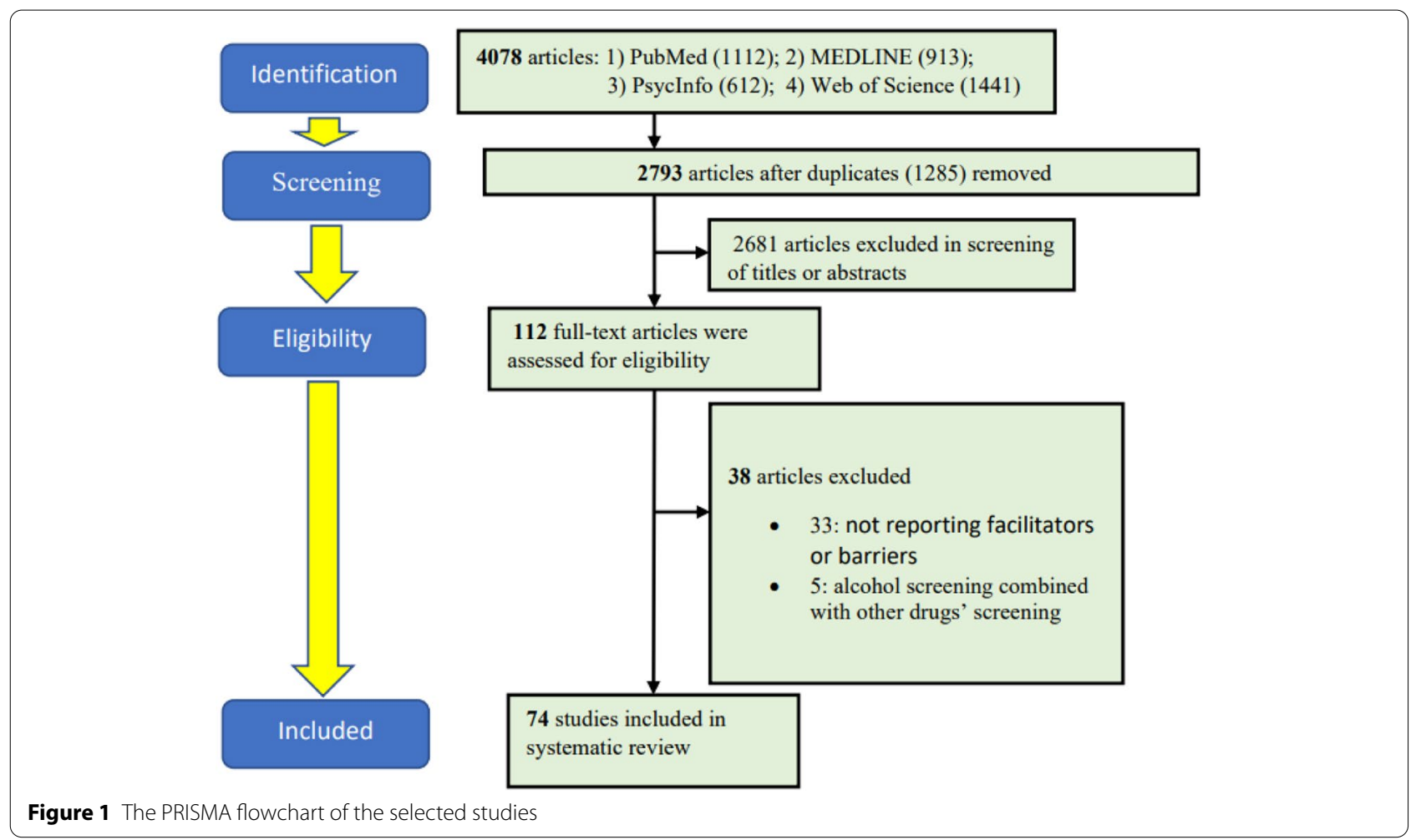

publication years, 10 studies were published before 2000, 39 were between 2000 and 2009, and 25 were after 2009 . The overall quality of the included studies was generally good, meaning that the studies satisfied most of the criteria (Additional file 2).

\section{Practice of SBI}

Although the analysis of the practice of SBI was not the main aim of this review, we tried to extract related information from the included studies and give a preliminary analysis in this area. Among the included studies, participants were asked about their current practice of SBI in 15 studies, and these studies were conducted in nine countries, i.e. Finland, the UK, Germany, the USA, France and South Africa, Sweden, Sri Lanka, and Canada (Additional file 3). The participants in these studies were all physicians, except in one study in which nurses were also included. There were two ways of measuring their practice: 1) had ever performed SBI; 2) performed SBI on a regular basis. The percentage of participants who reported that they had ever performed screening or brief intervention ranged from $45.0 \%$ to $100 \%$. However, the percentage was much lower when it was on a regular basis, which ranged from $9.4 \%$ to $40.0 \%$, except for one study with $75.0 \%$. Regarding whether they had performed SBI, the highest rate was found in South Africa (100\%), the UK (98.0\%), the USA $(95.0 \%$ and $84.0 \%$ in two studies), France (94.1\%), and Germany (84.2\%), whereas the lowest rate was found in Finland (45.0\%). For regular basis, the highest rate was found in Canada (75.0\%) and the UK (40\%) whilst the lowest rate was found in Finland (9.4\%) and Sri Lanka (15.0\%).

\section{Facilitators and barriers of SBI implementation based on the CFIR}

The following results are presented according to Table 2.

\section{Intervention characteristics}

Evidence strength was considered by primary healthcare providers when implementing SBI. About $74-81 \%$ of physicians in the UK and Poland agreed that the proven efficacy of early alcohol intervention was a facilitator of implementing SBI [15, 60, 93], whilst doubt about the effectiveness of brief interventions was cited as a barrier to implementing SBI by physicians or nurses in the USA, the UK, and Finland [21, 23, 26, 46, 56, 90]. For adaptability, physicians, nurses, and other health professionals (e.g. social workers, psychologists) in the USA, Catalonia, the Netherlands, Poland, Sweden, and the UK suggested that SBI could be adapted or refined to meet special needs, such as using computer-based methods for screening, targeted rather than universal screening (e.g. new patient registrations, general health checks, and particular types of consultations) $[26,56,74]$. Perceiving SBI 


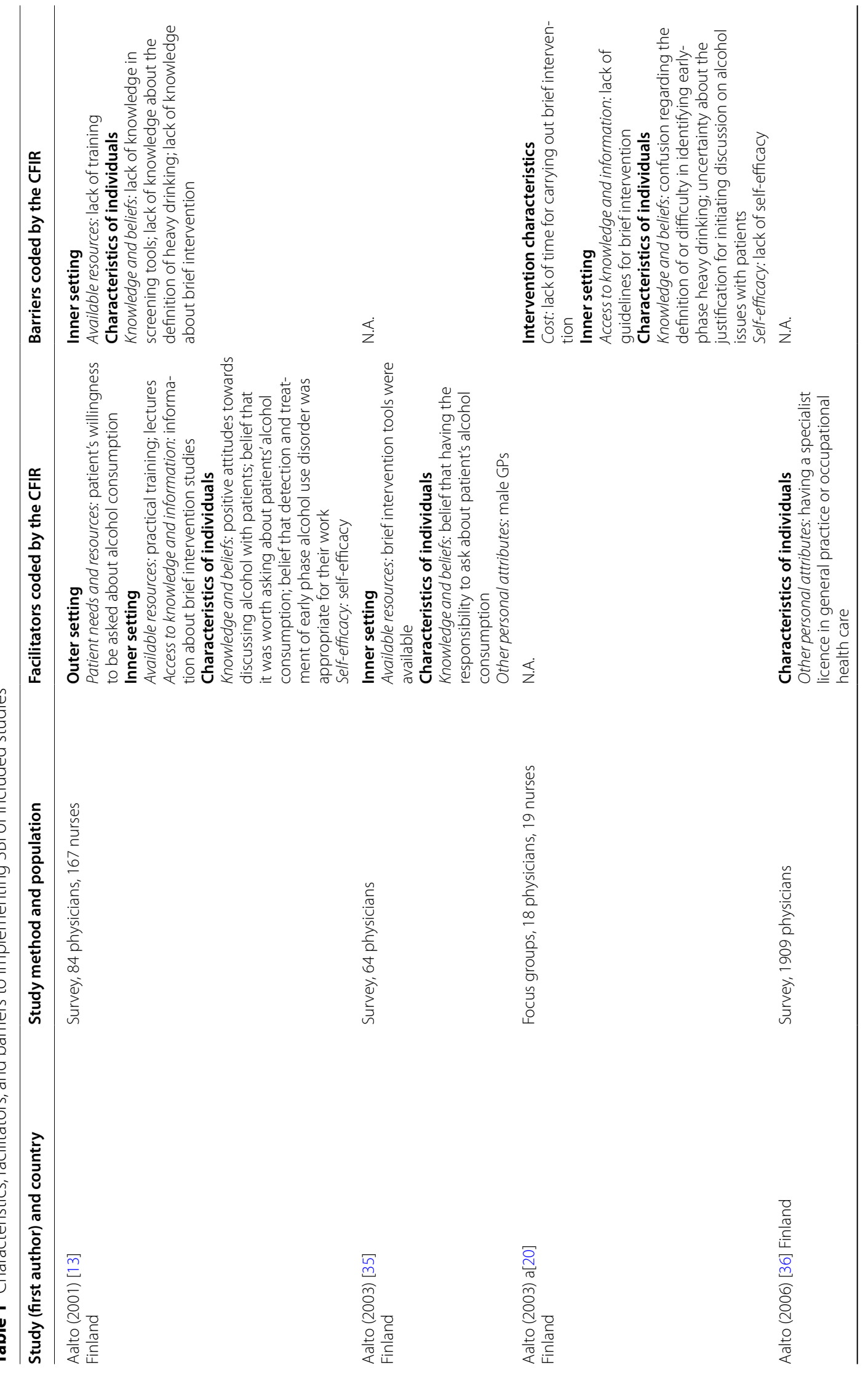




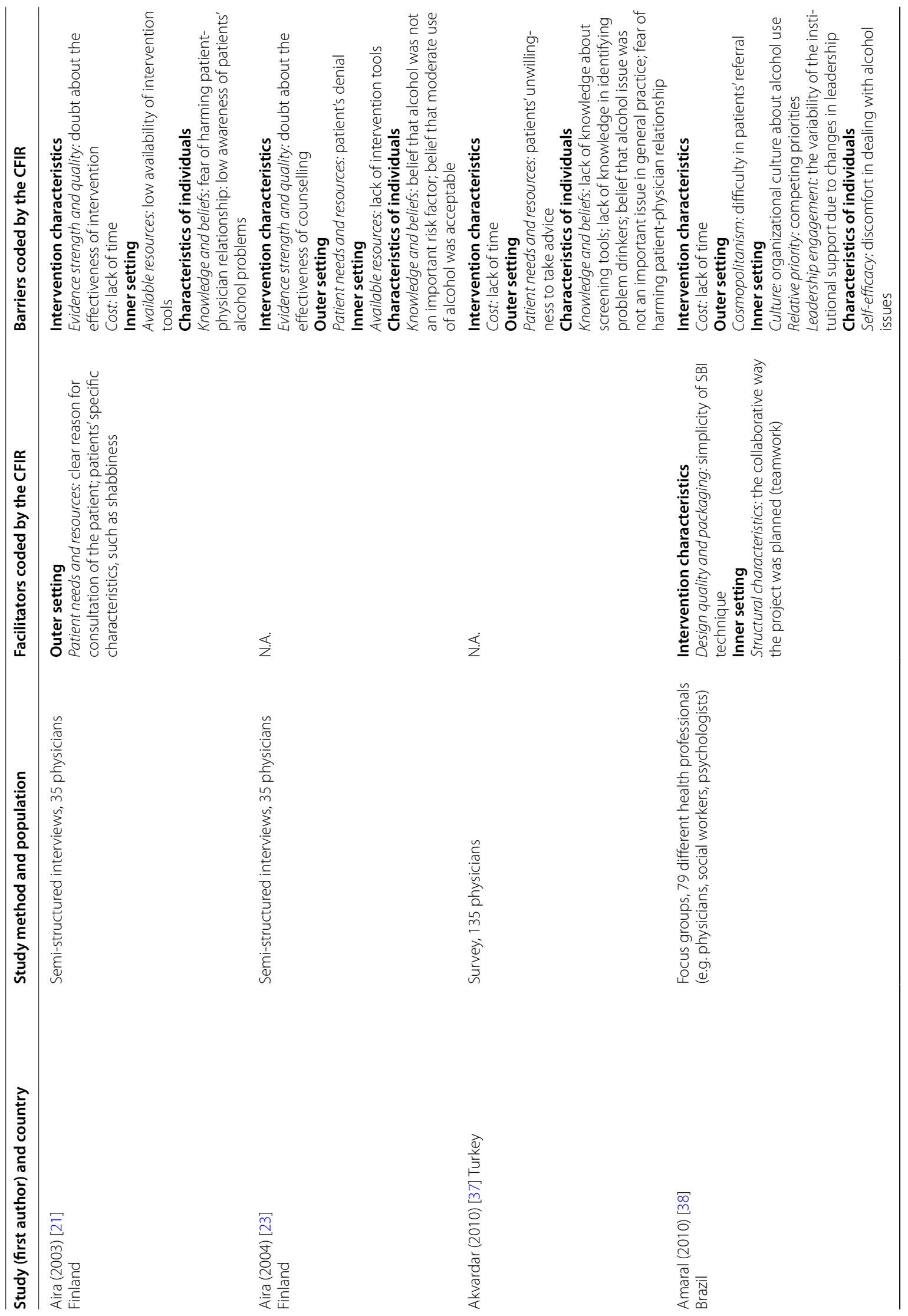




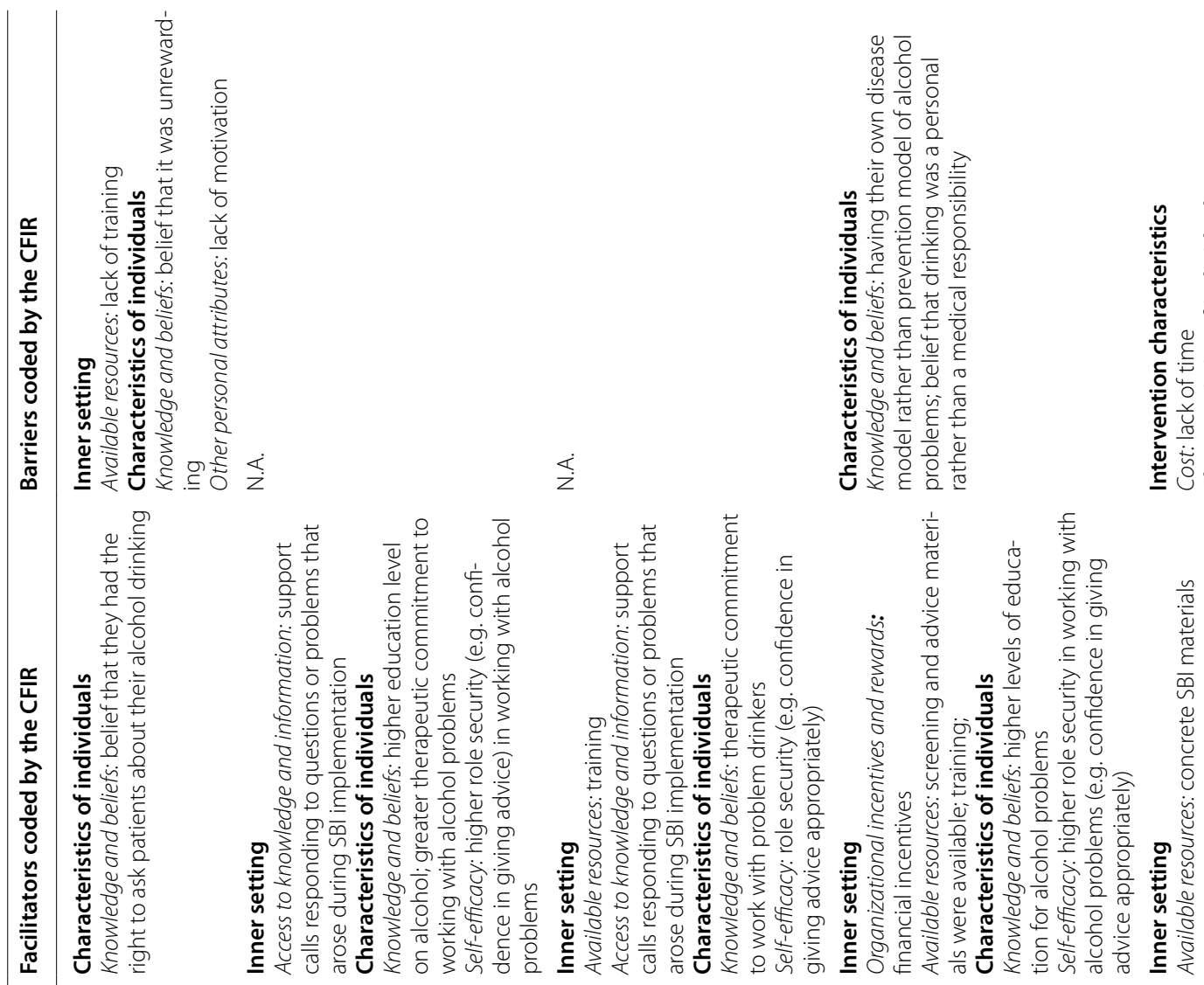

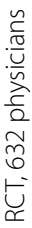

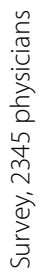

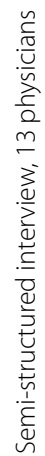
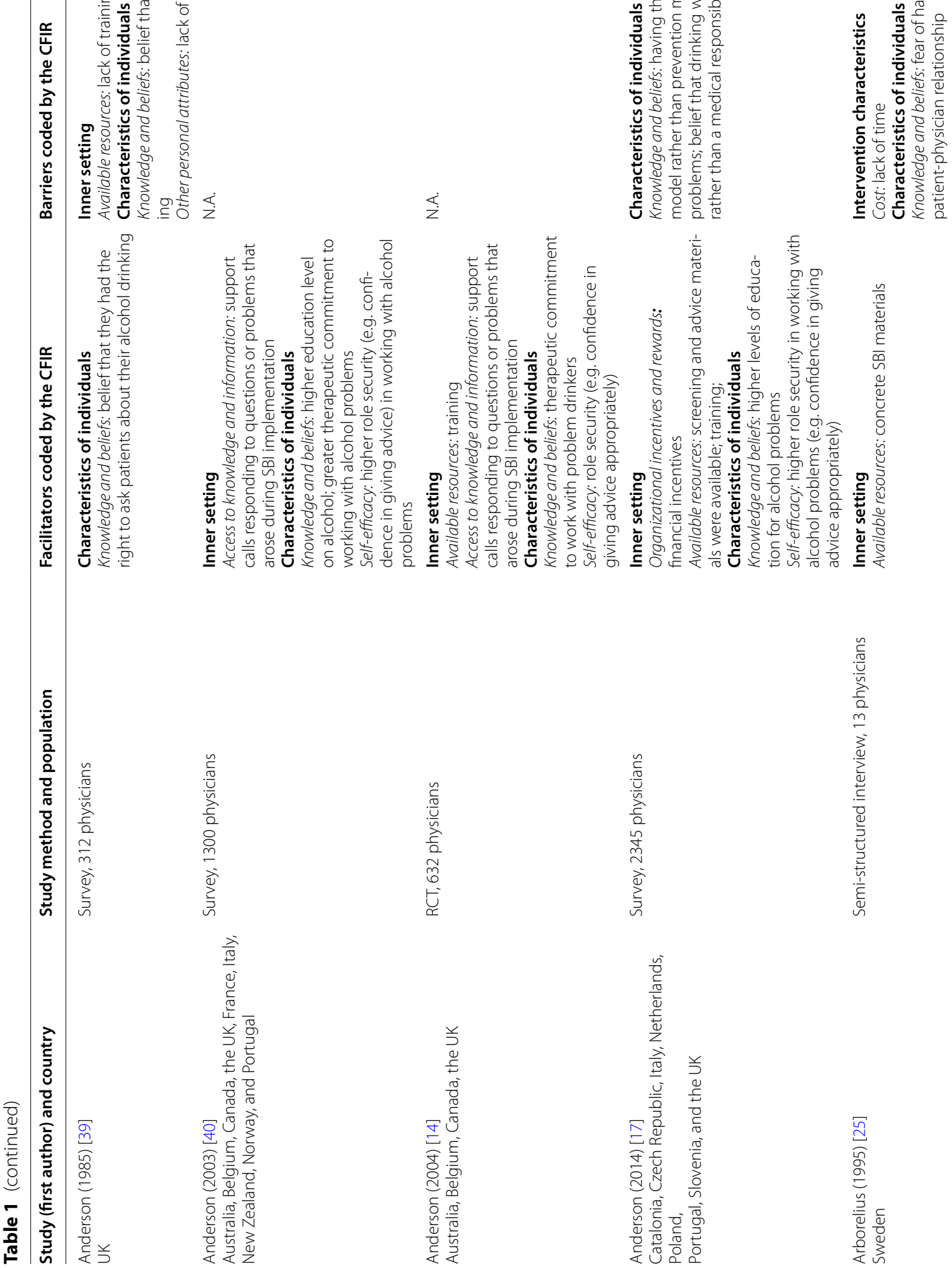

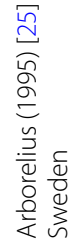




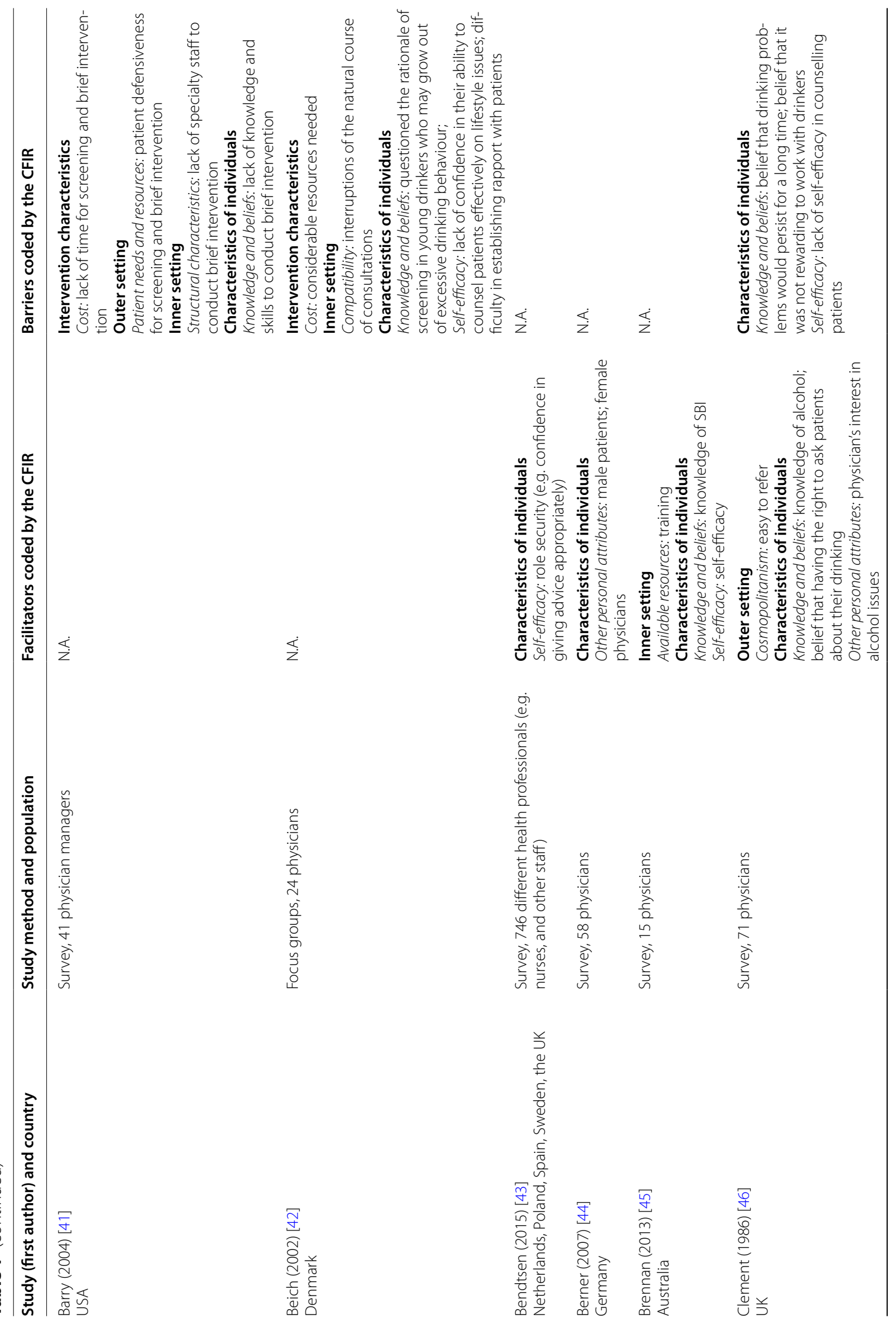



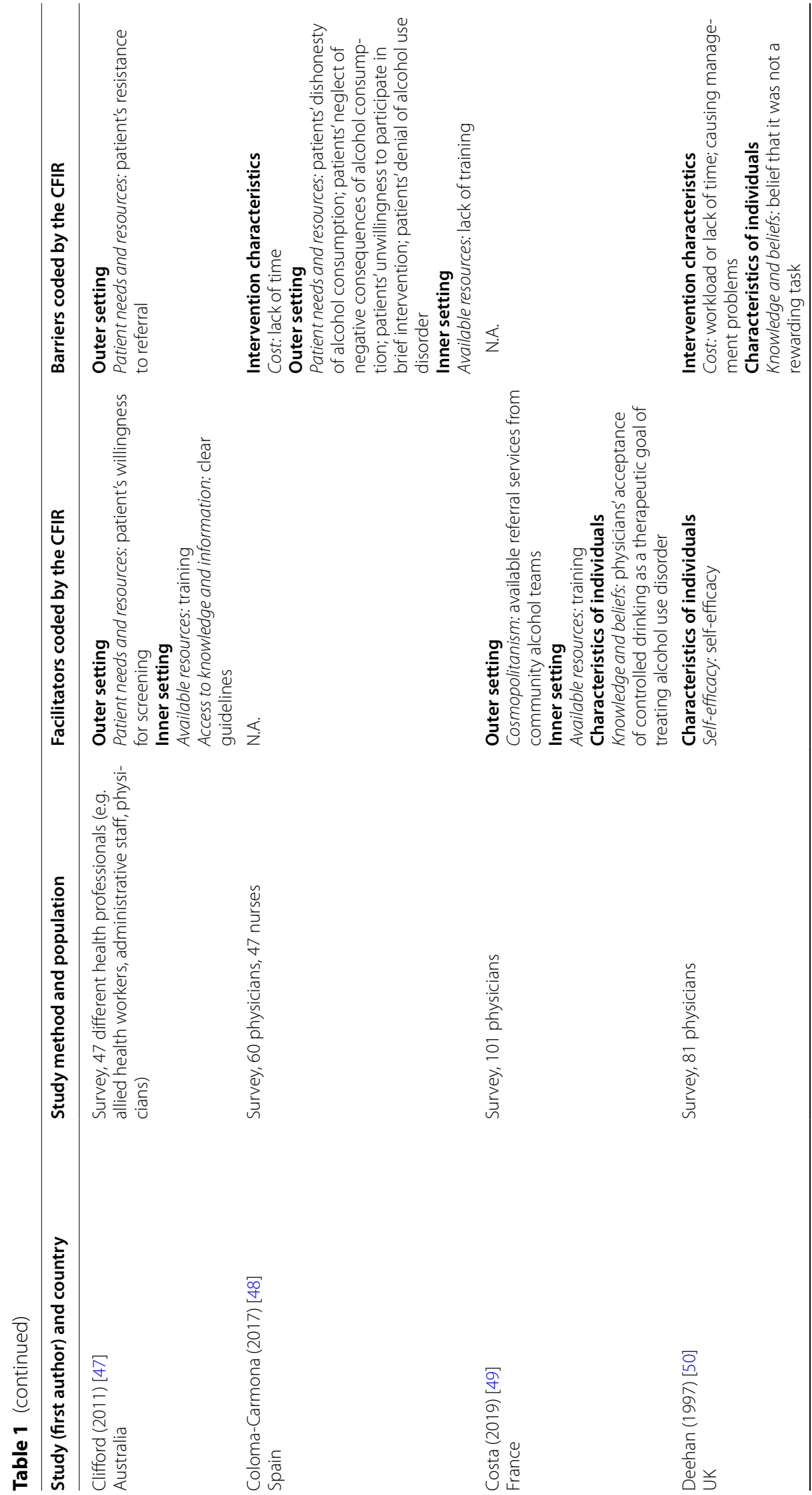

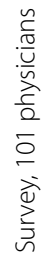

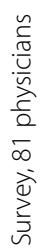
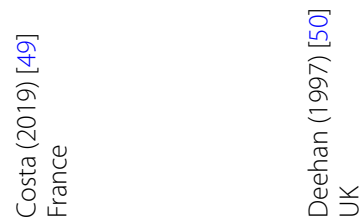

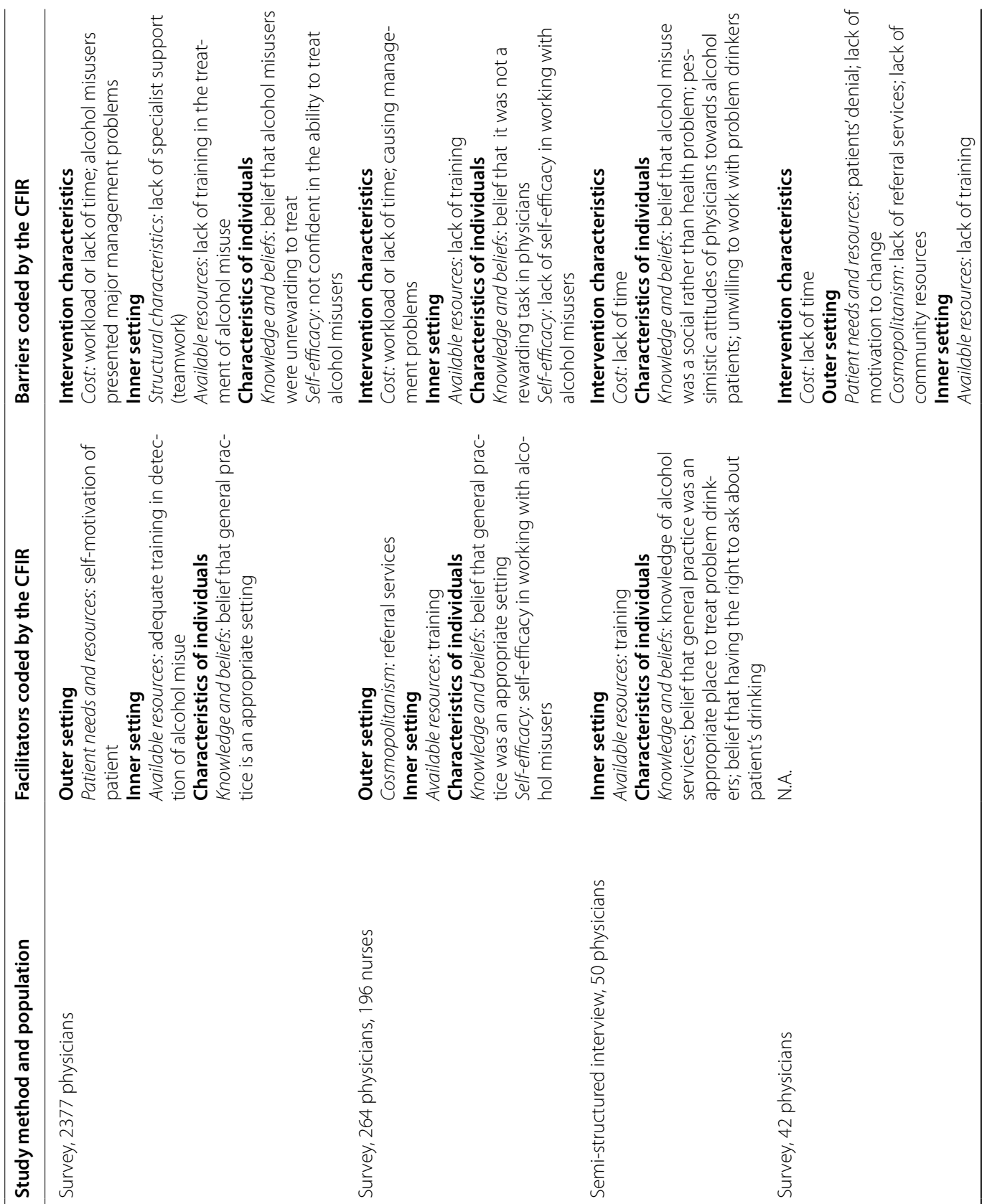

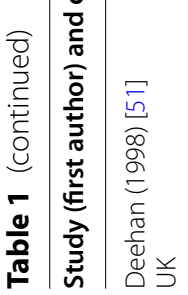
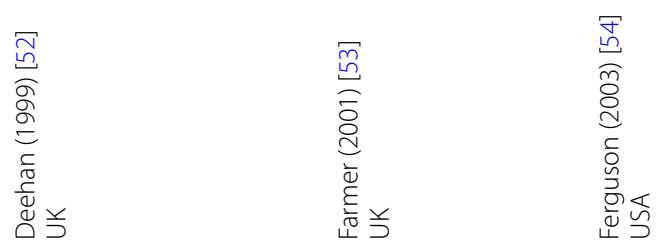


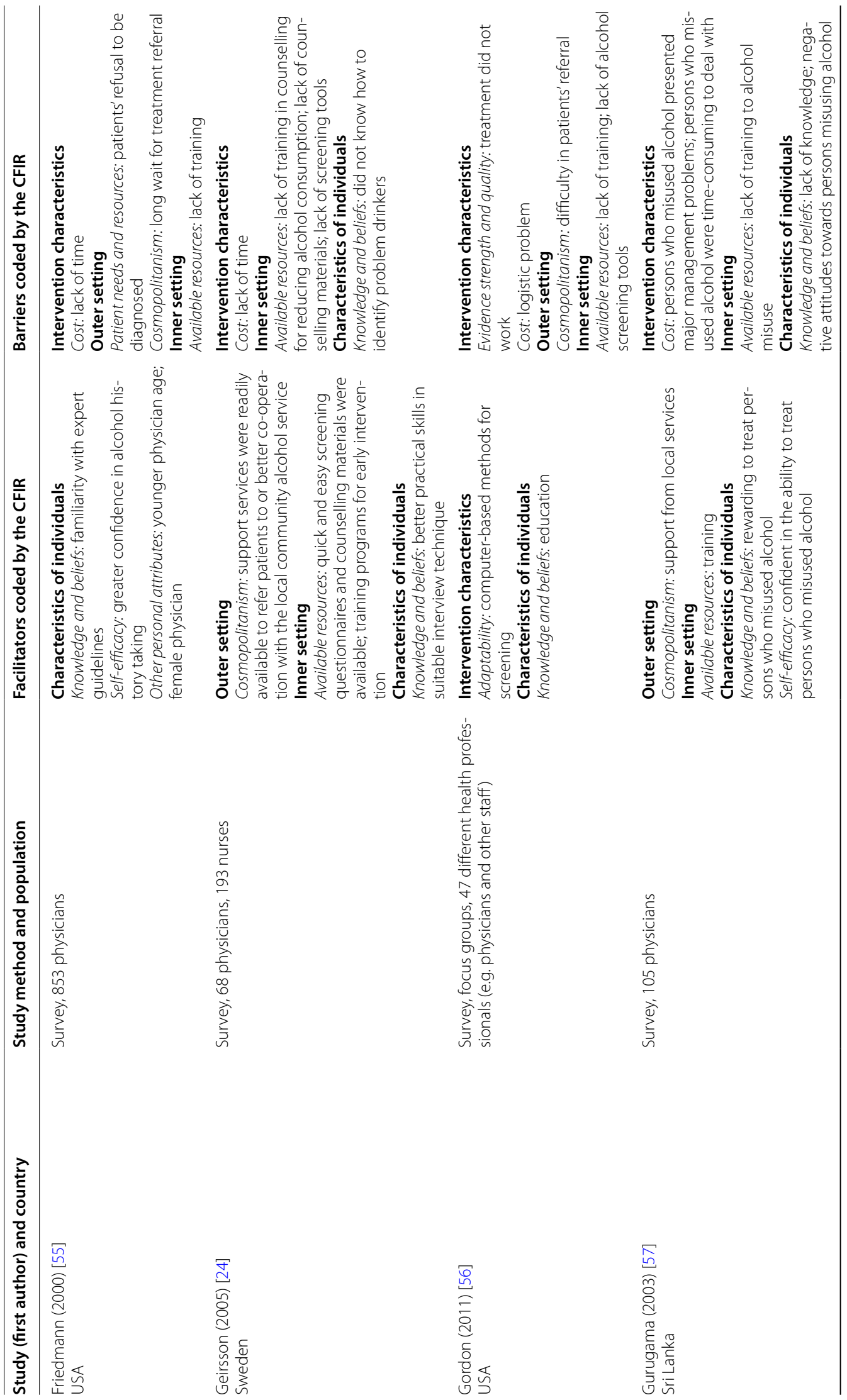



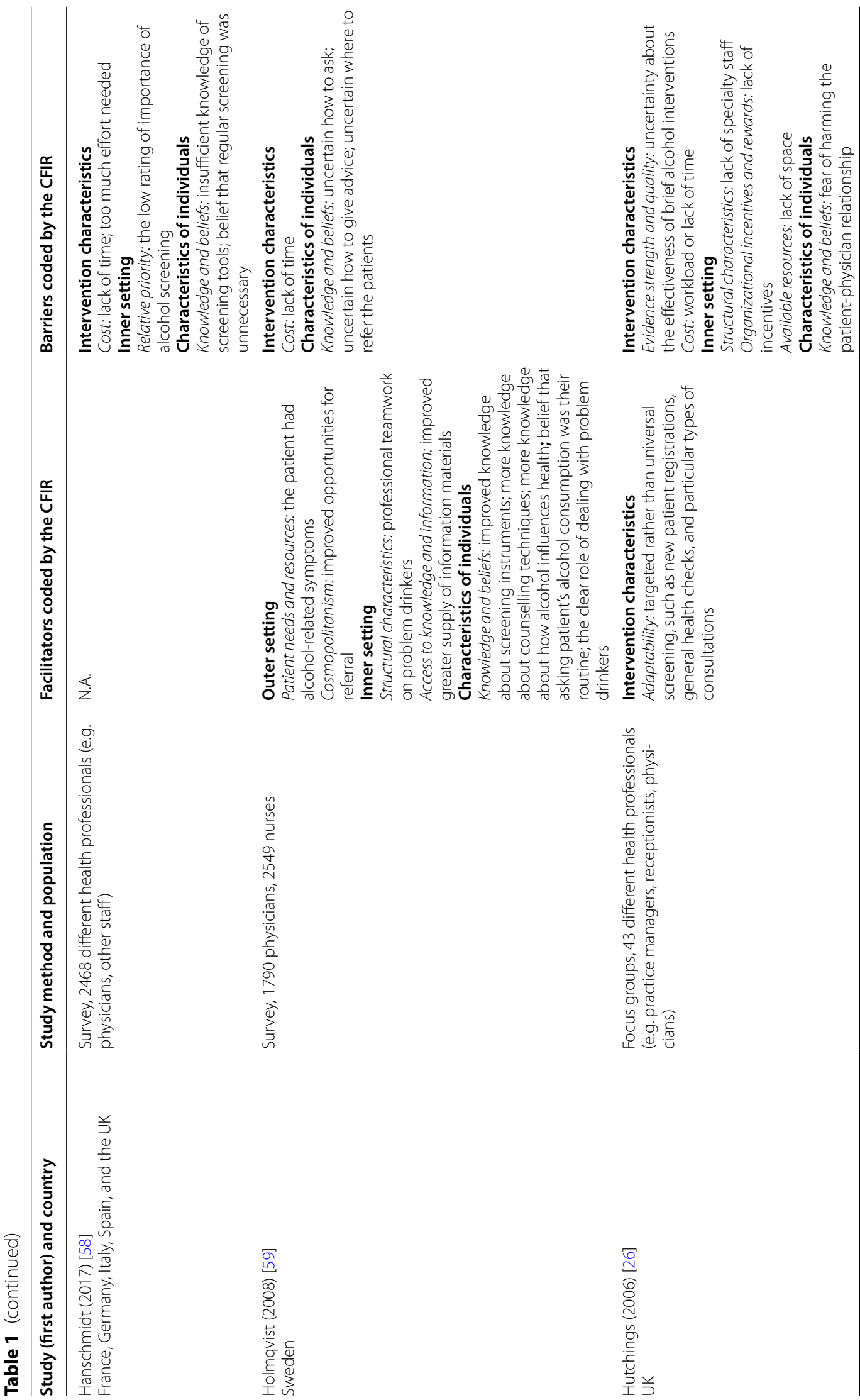


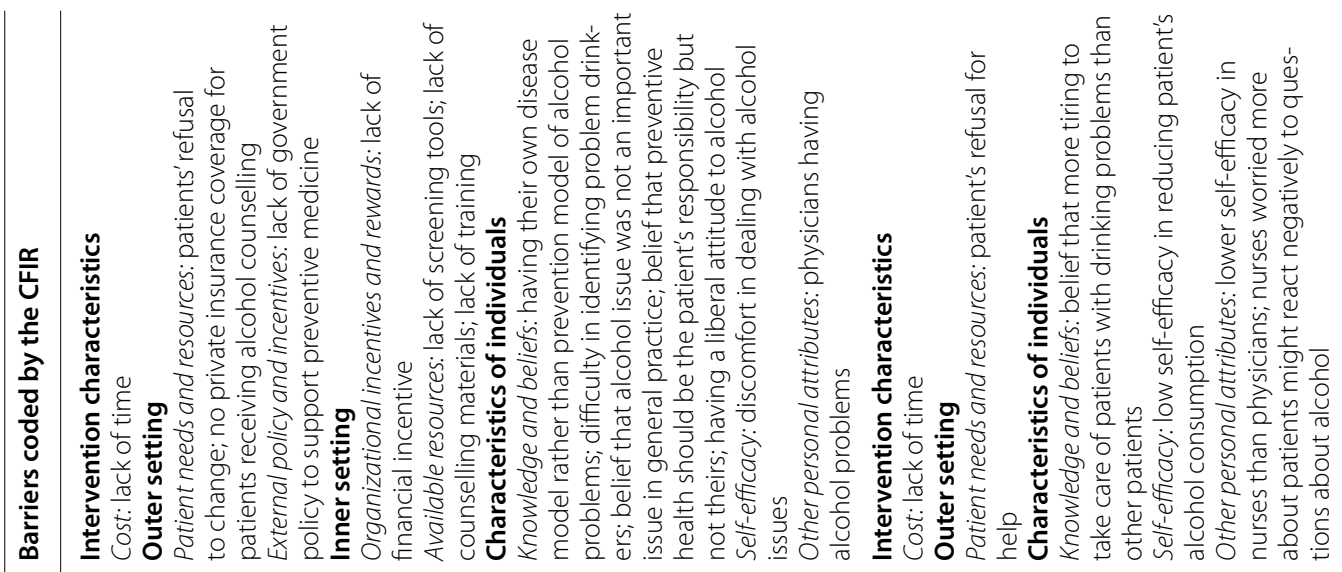

(a)

(⿰氵)
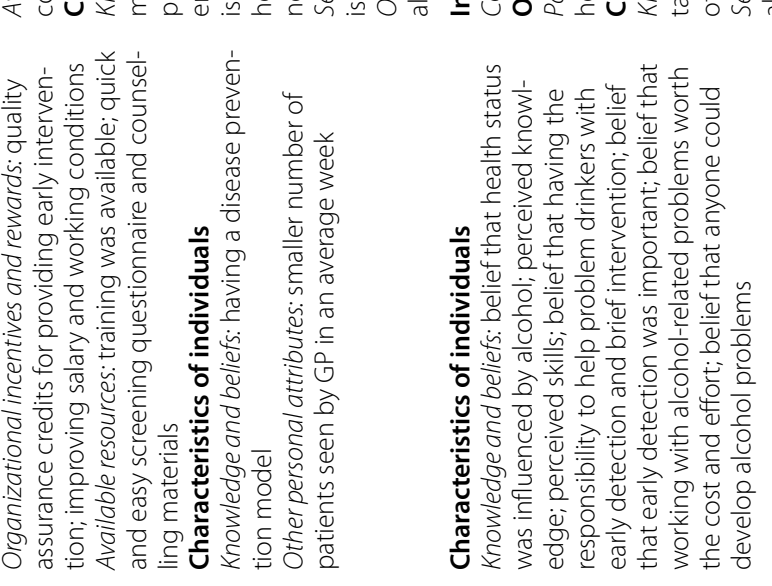


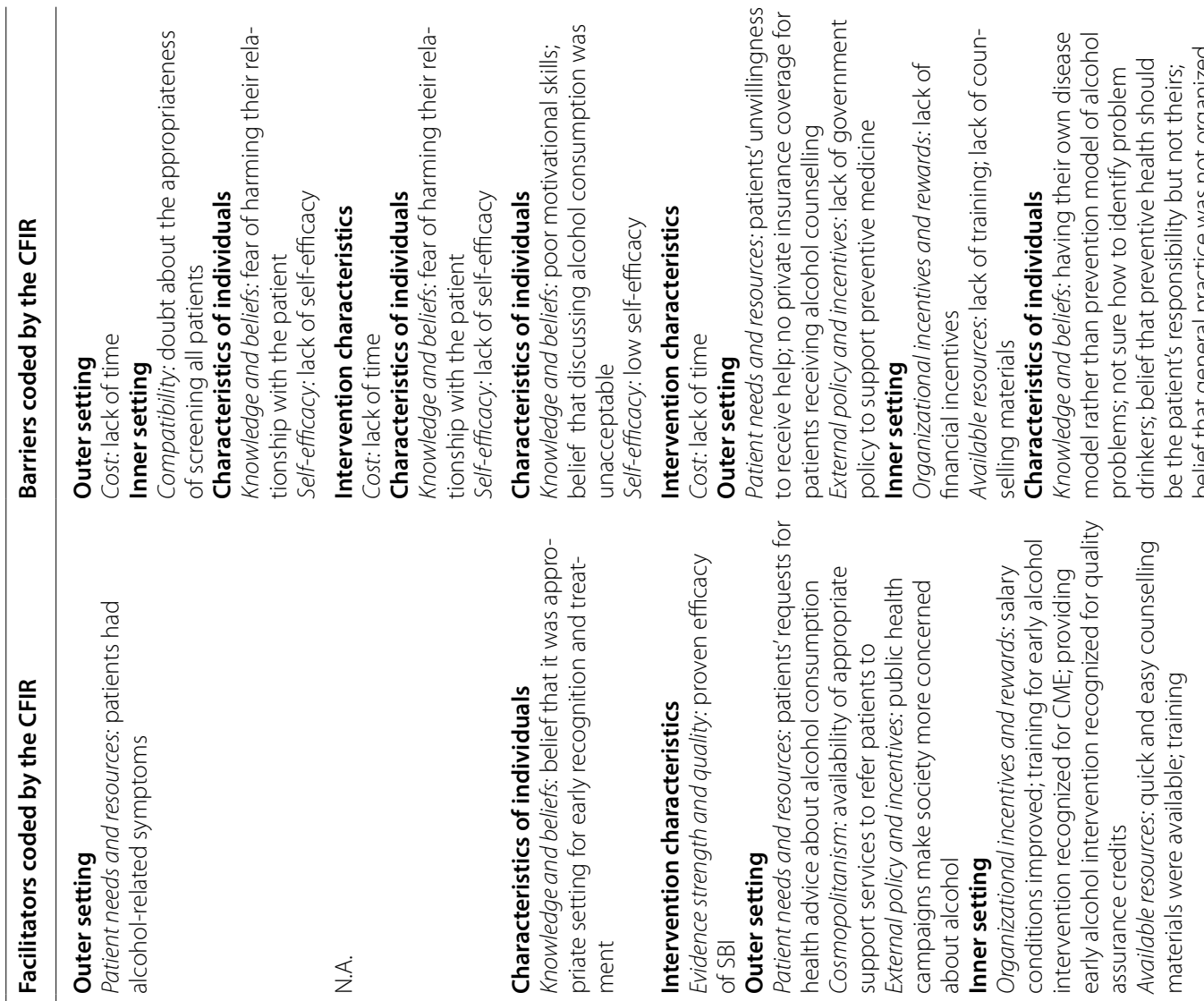

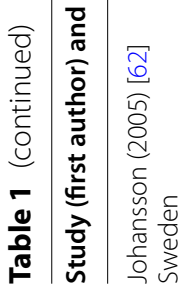

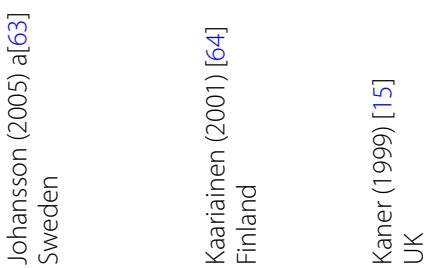




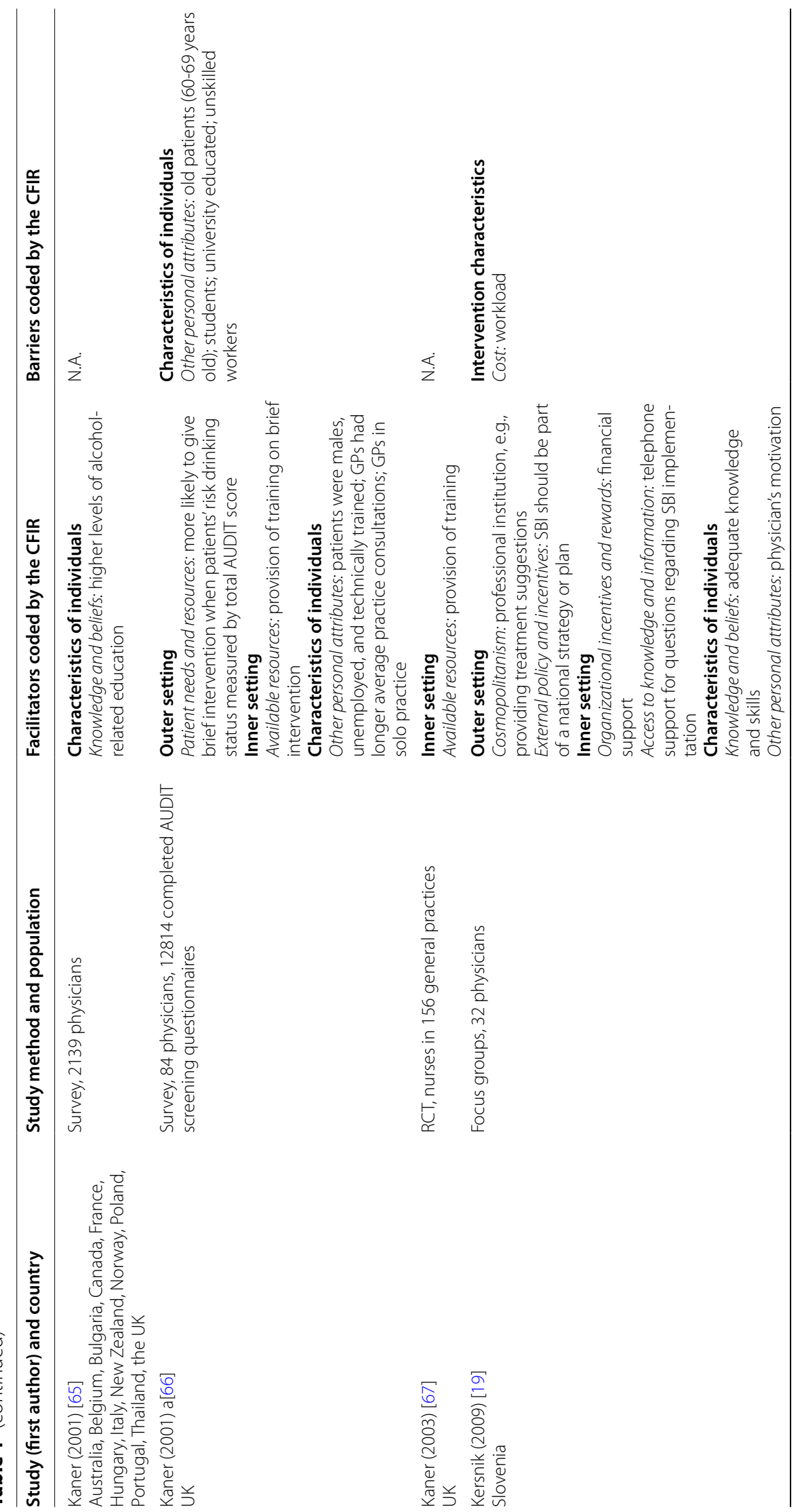




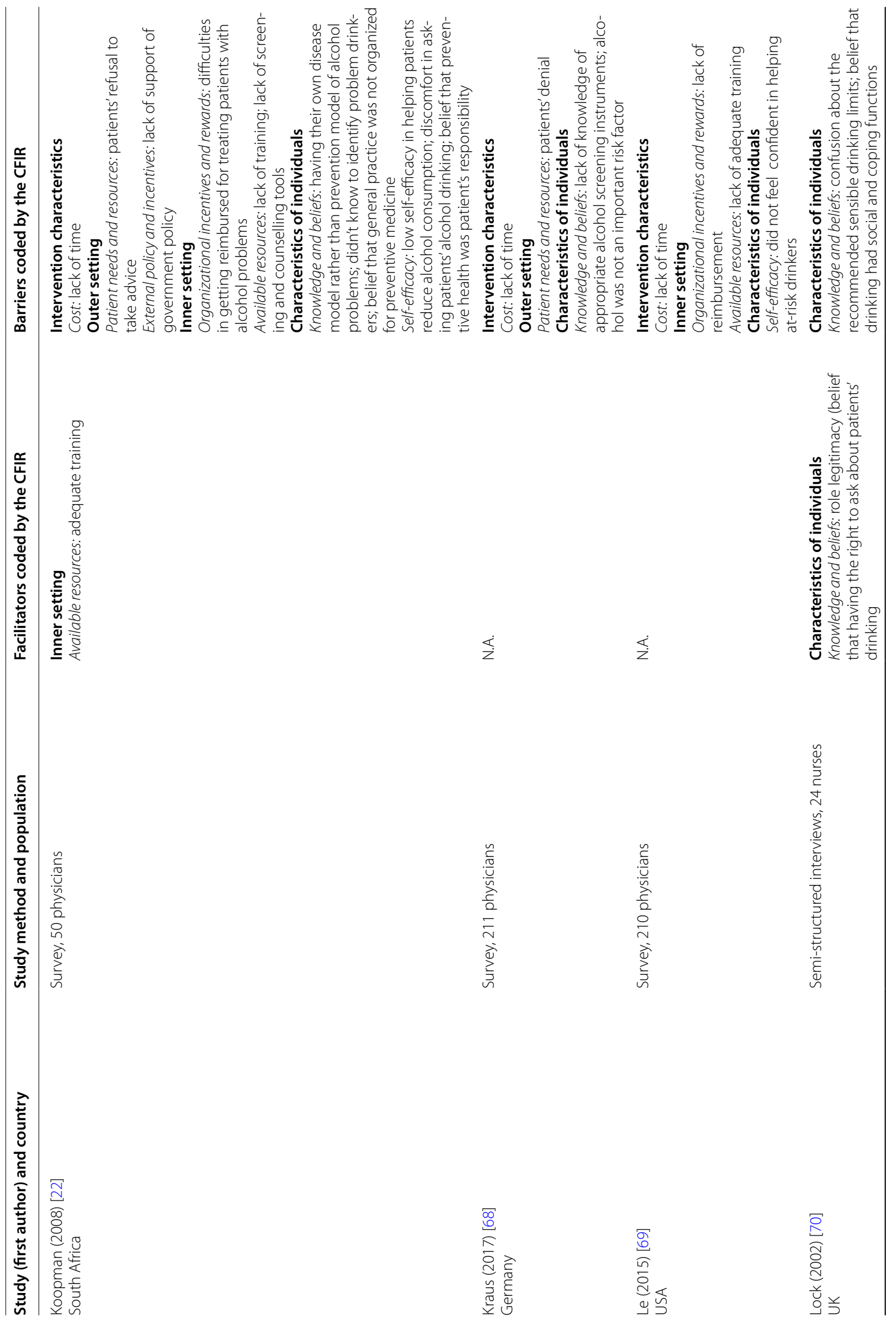




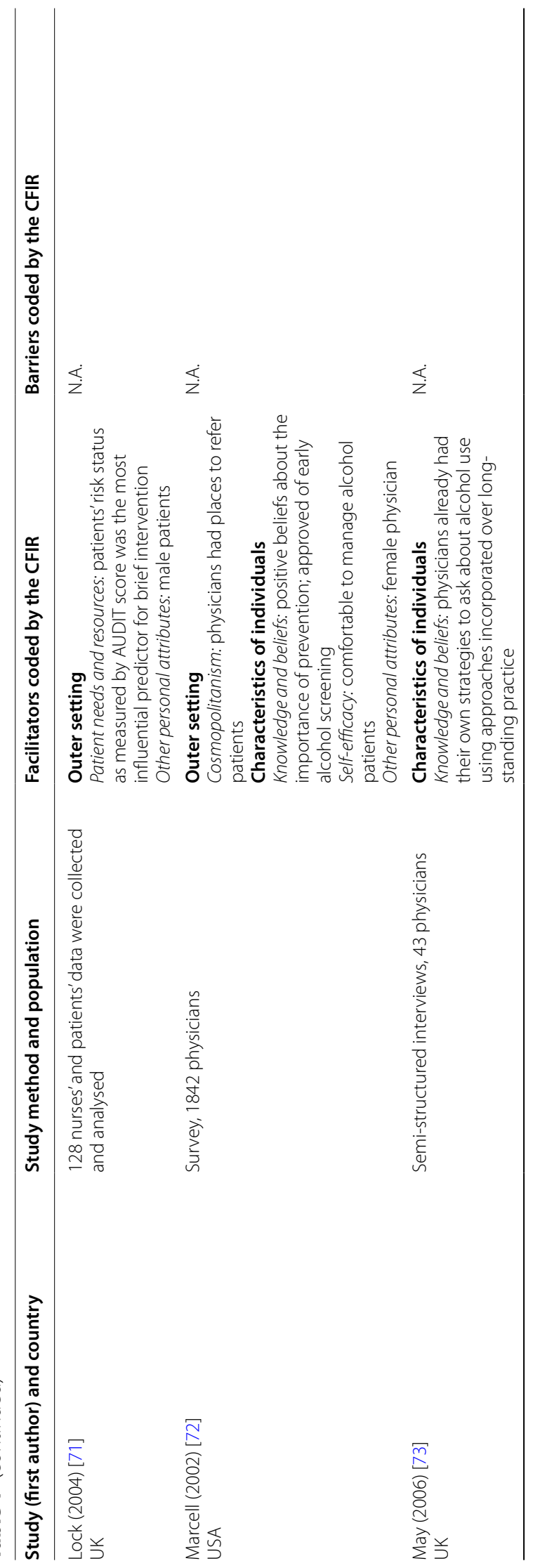




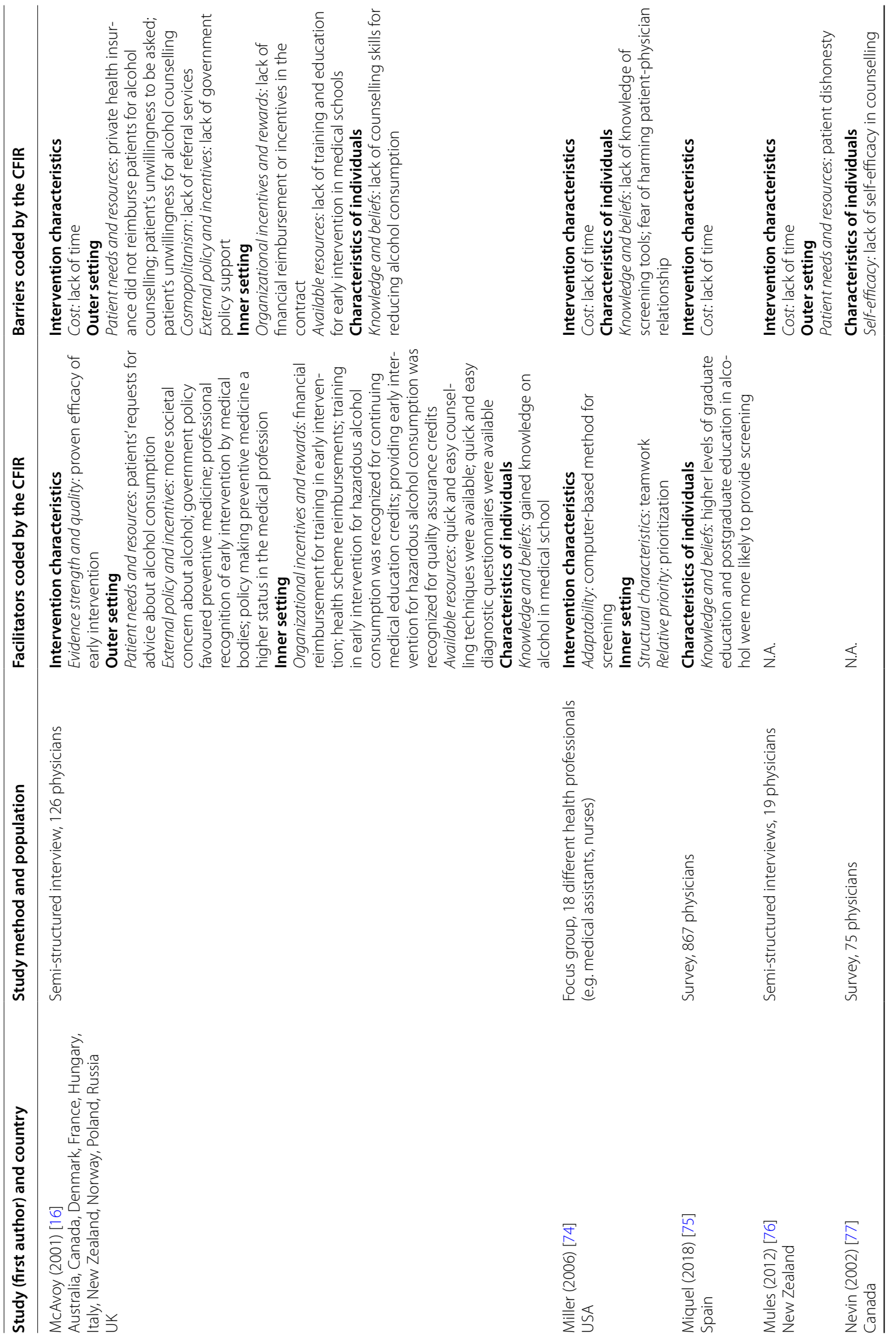



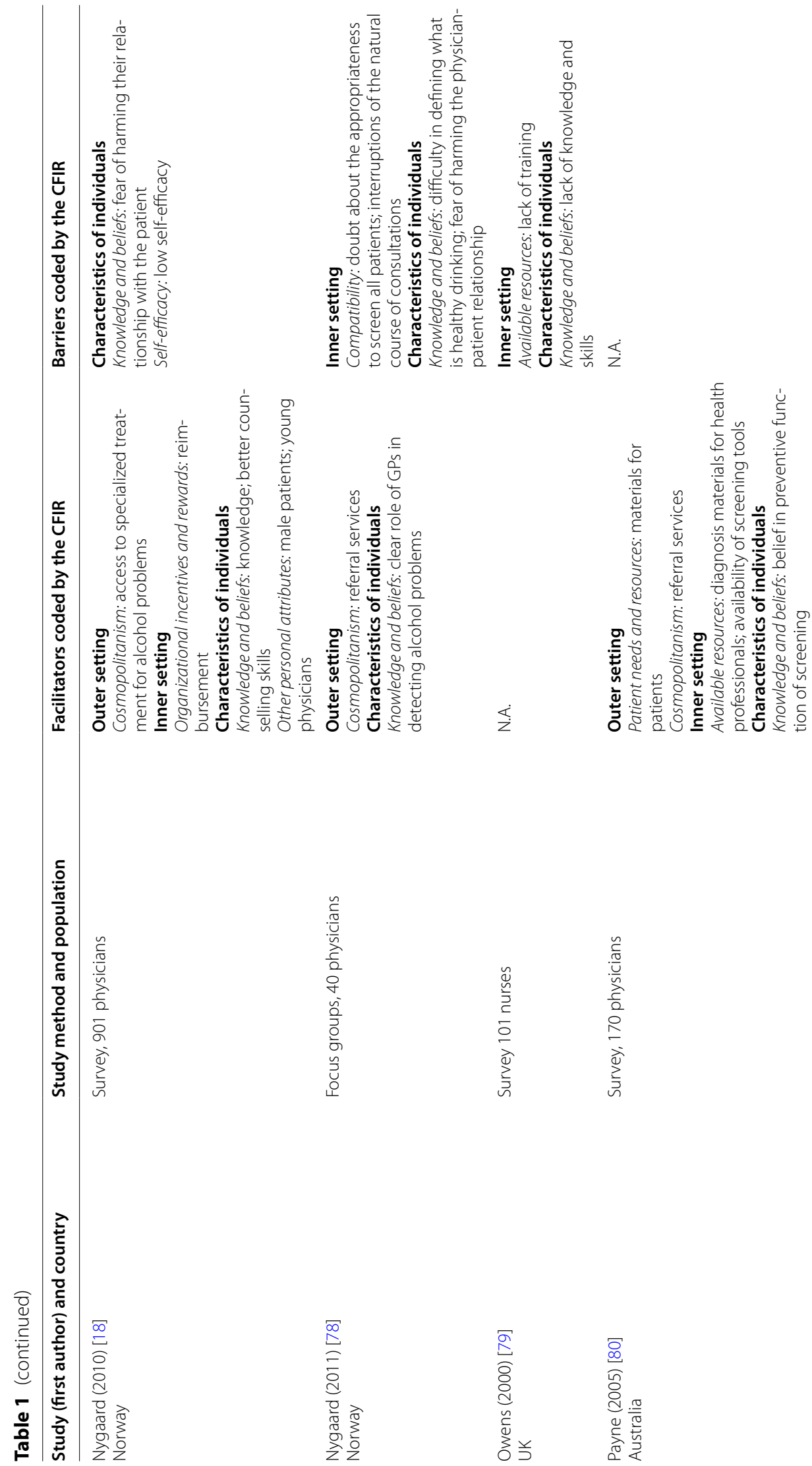

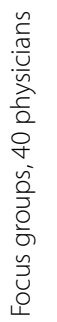
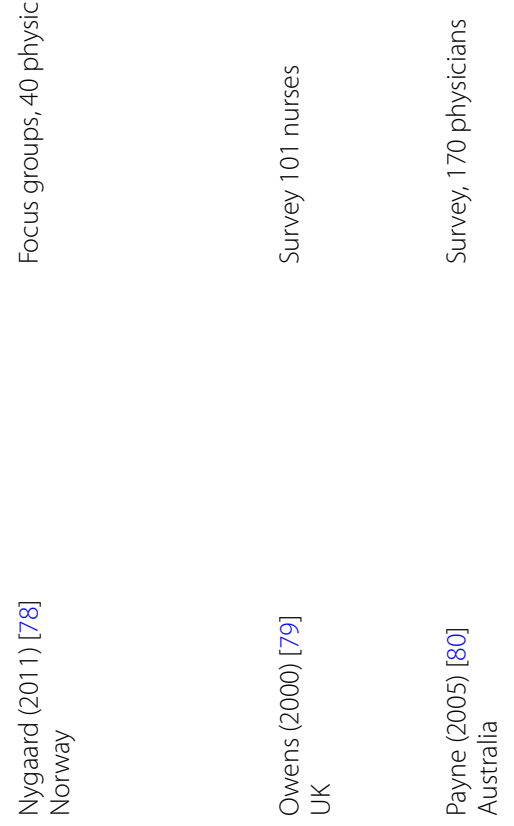

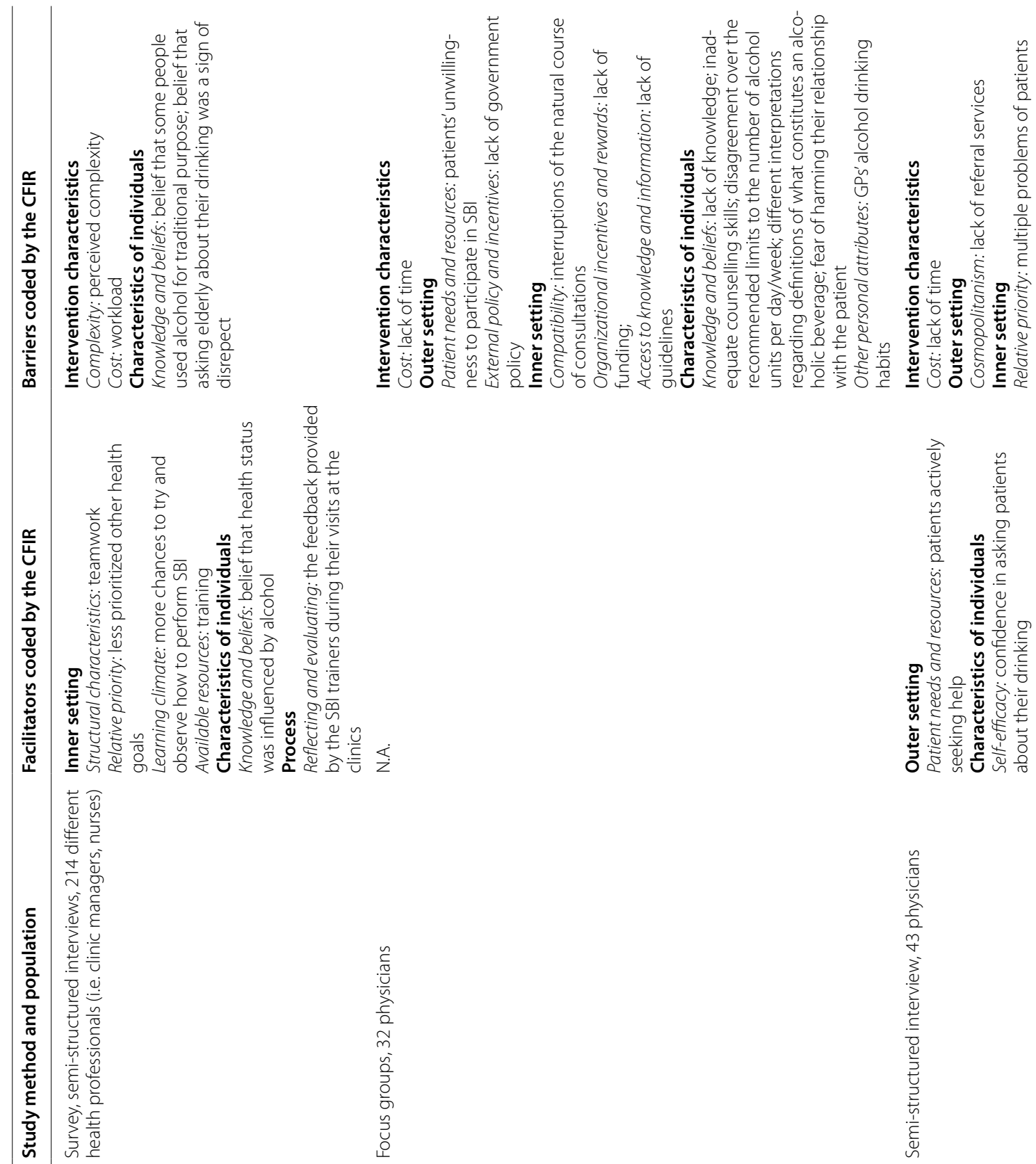

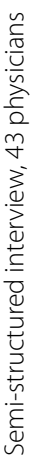

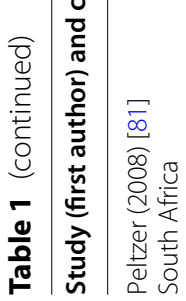
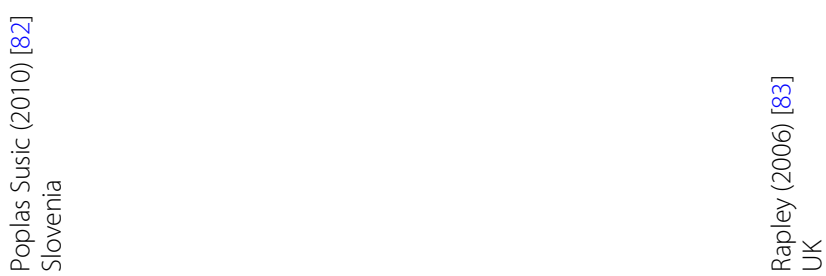


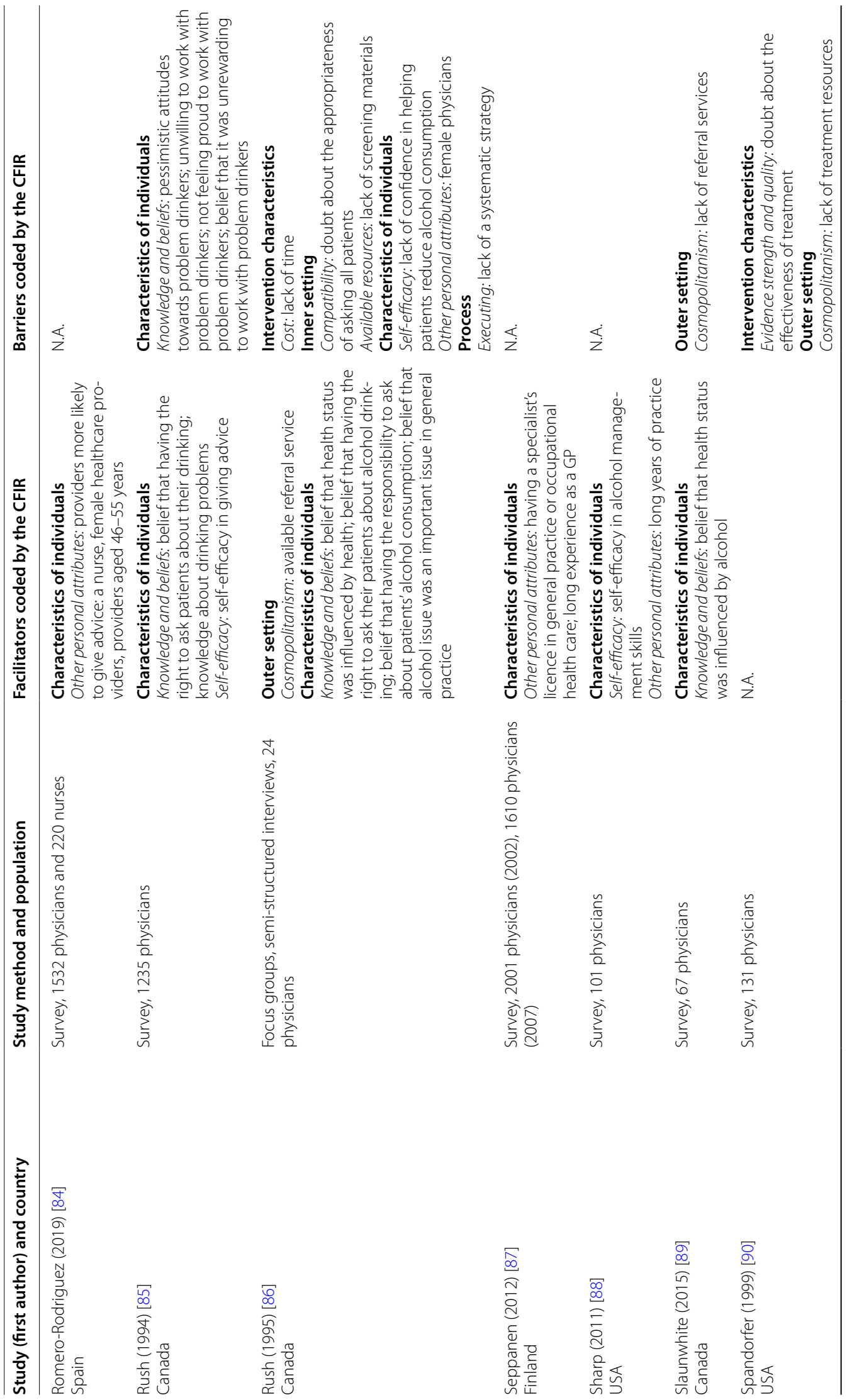




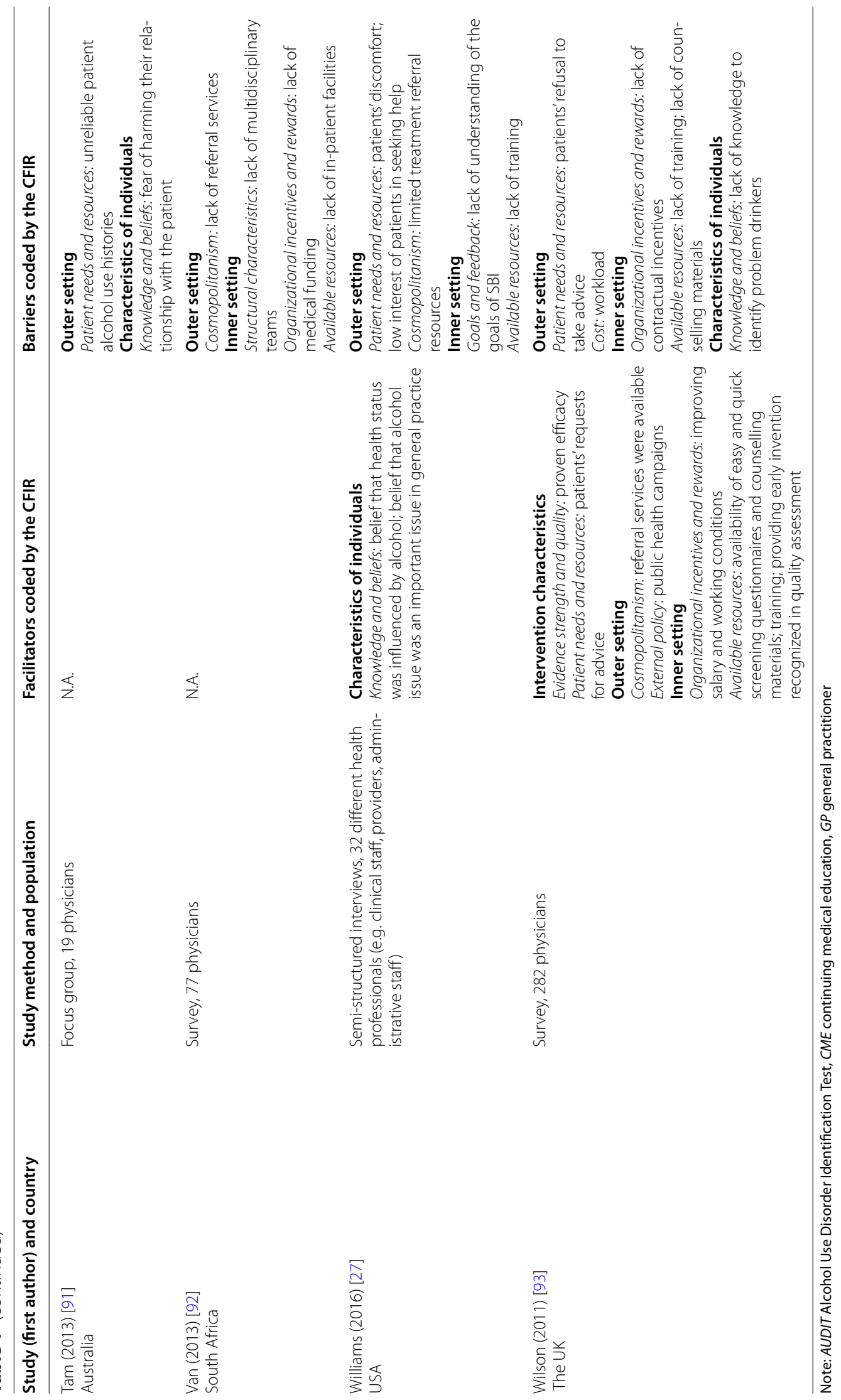




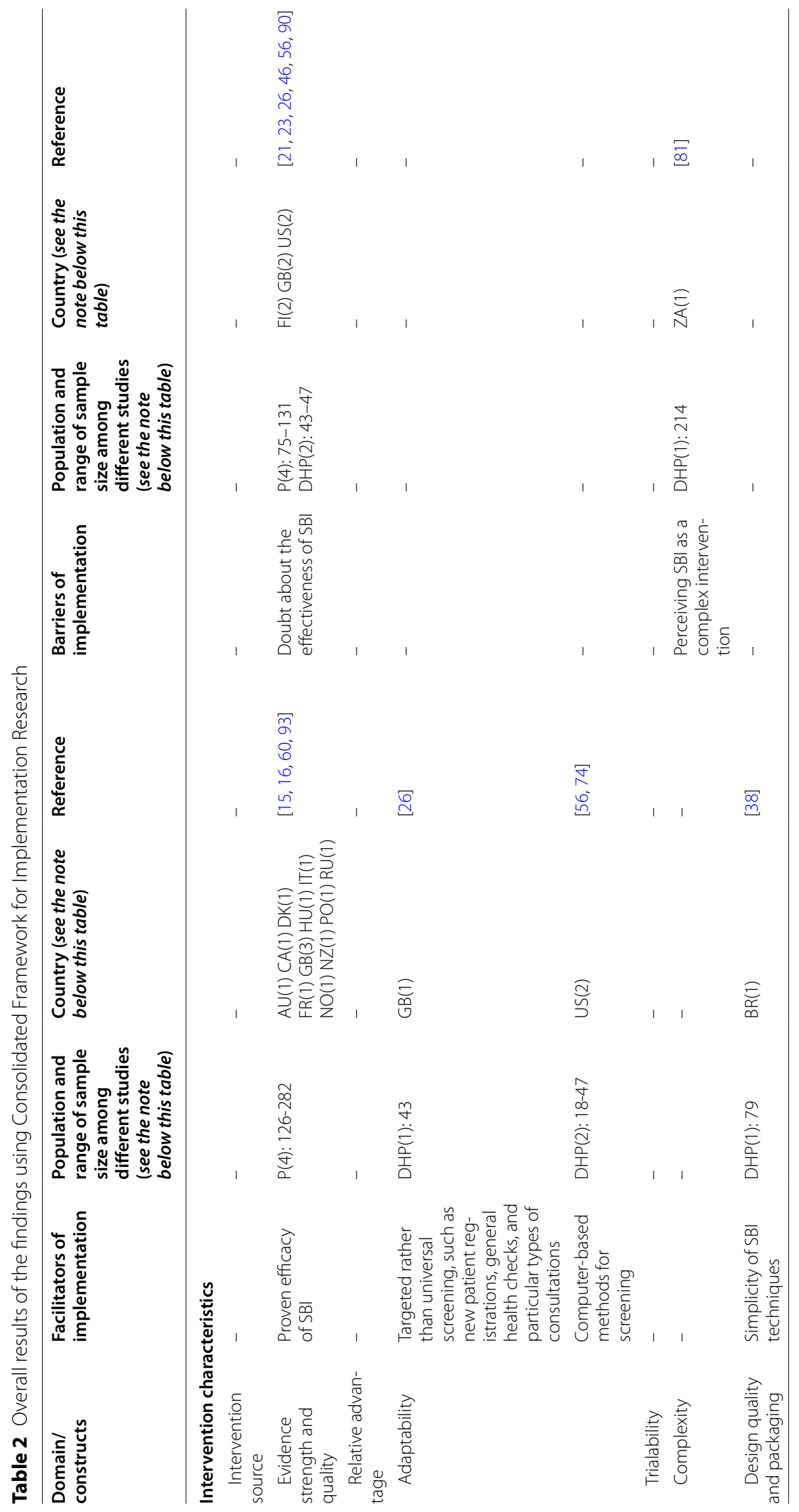




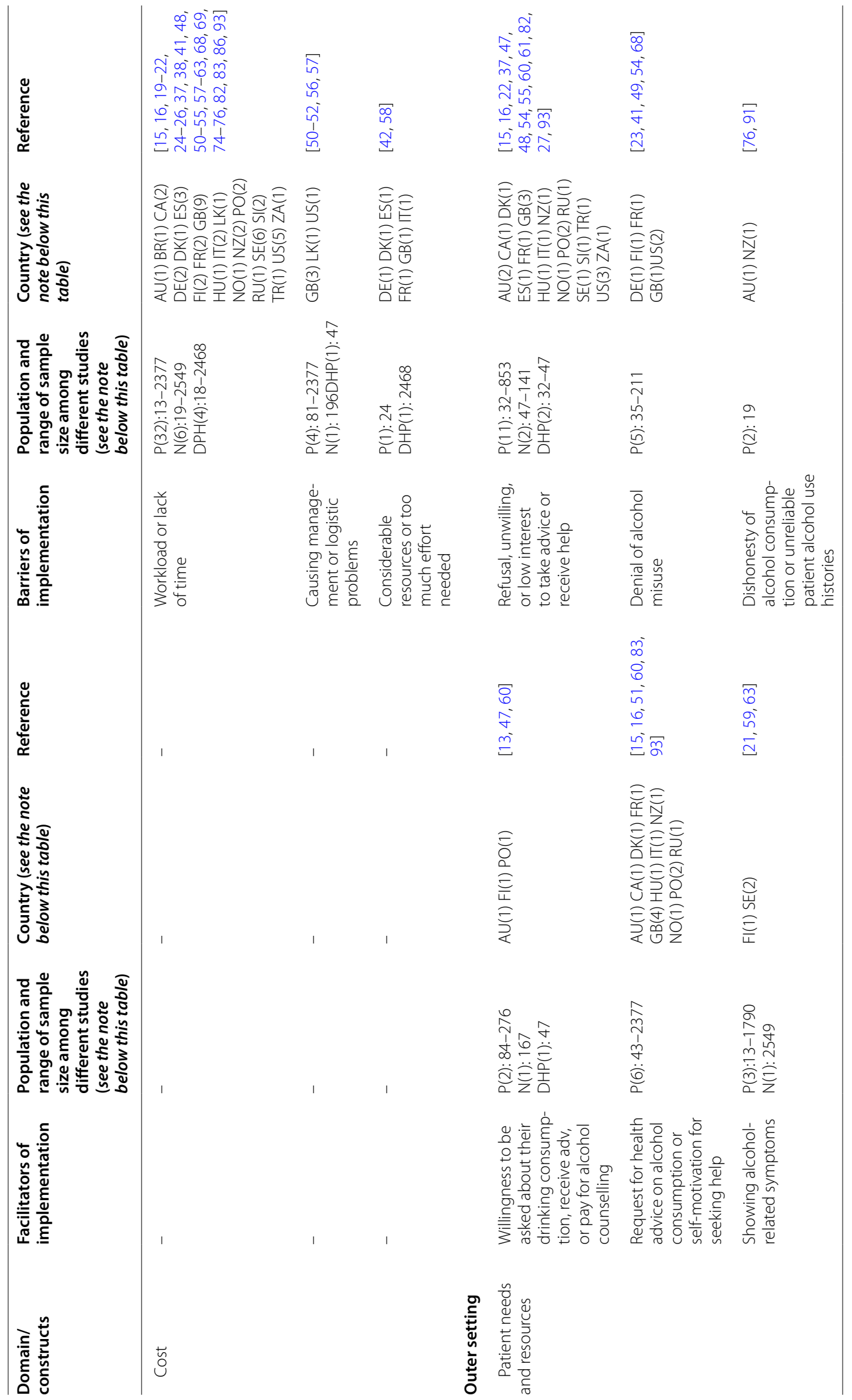




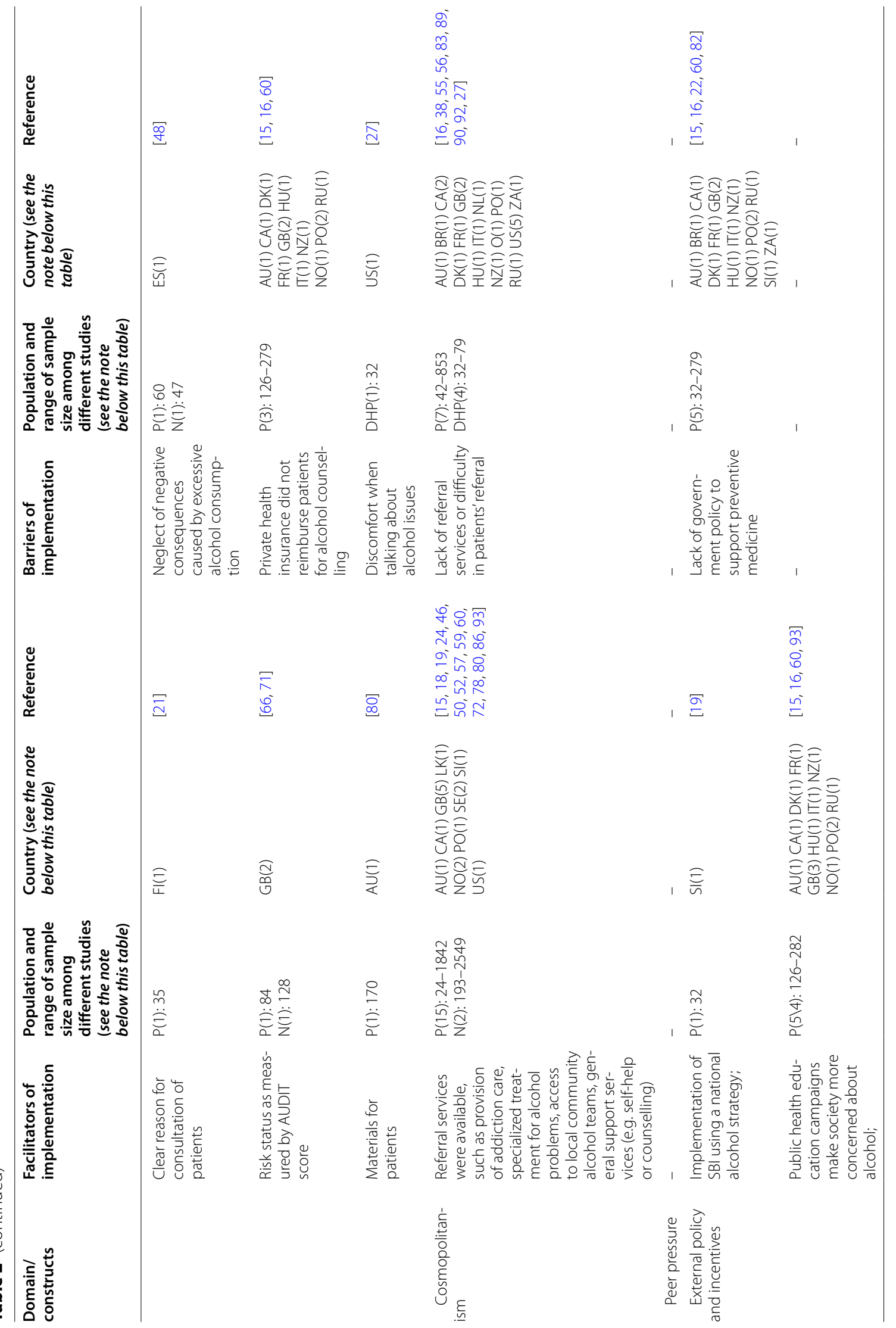




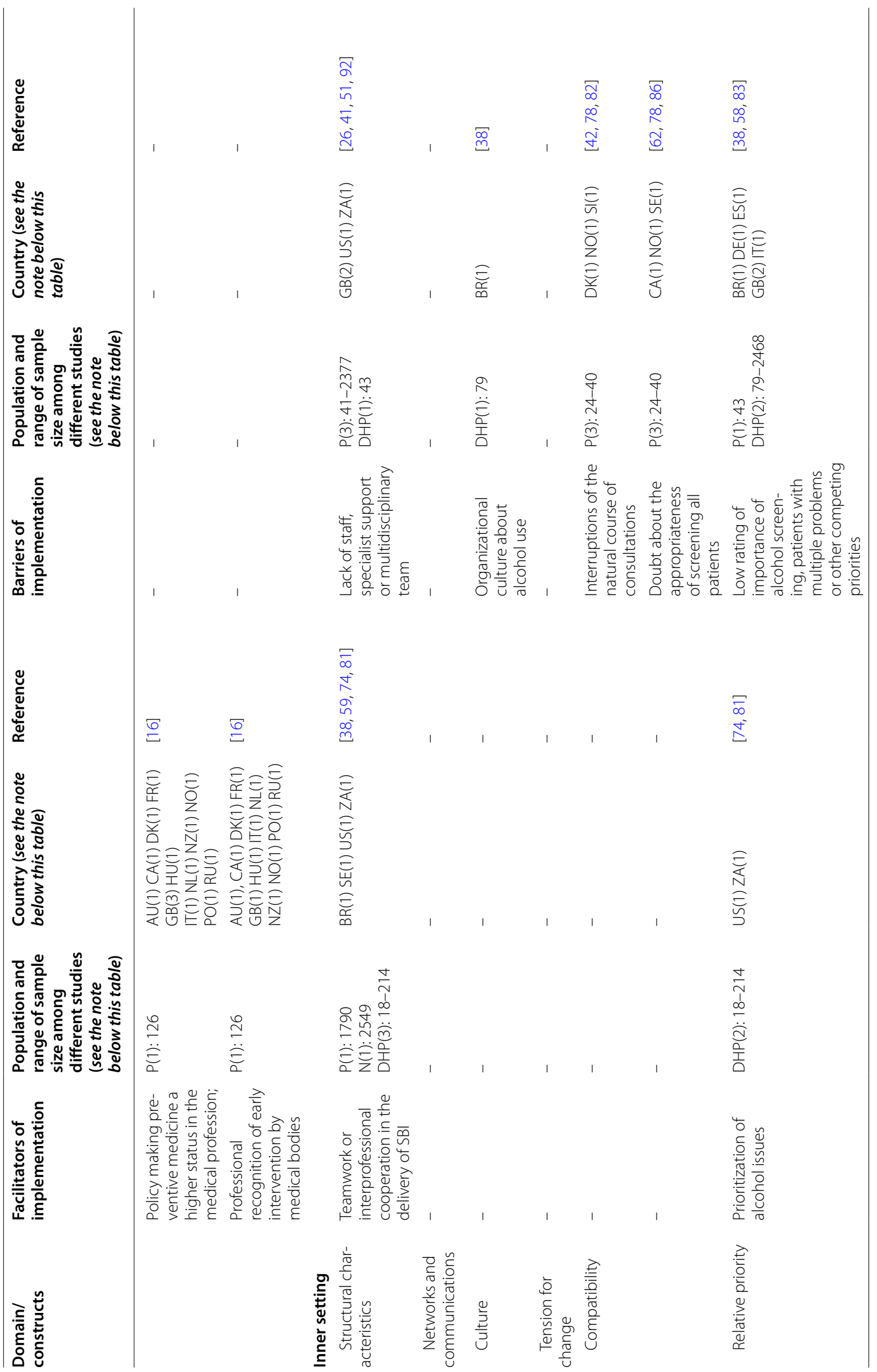




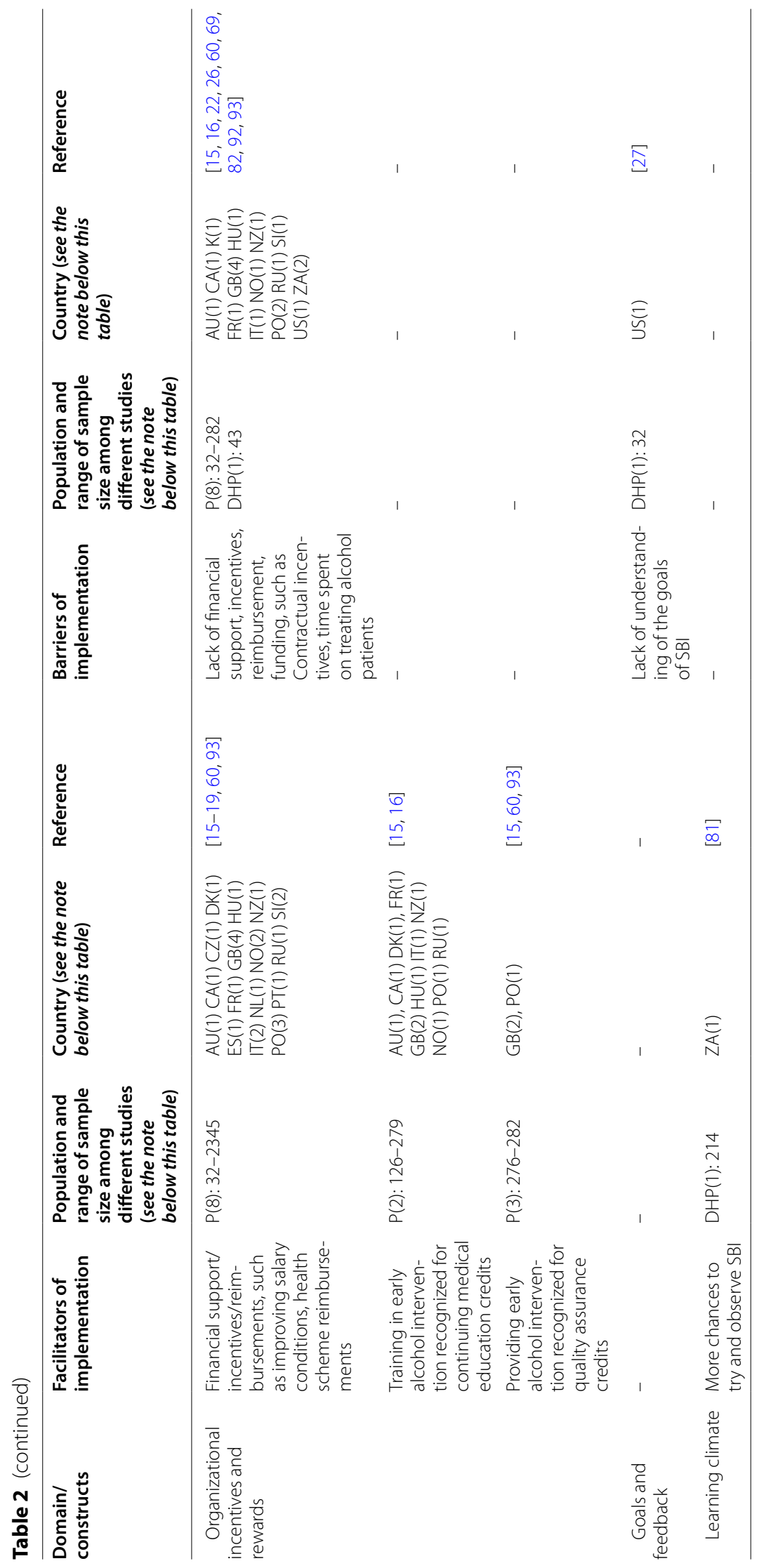




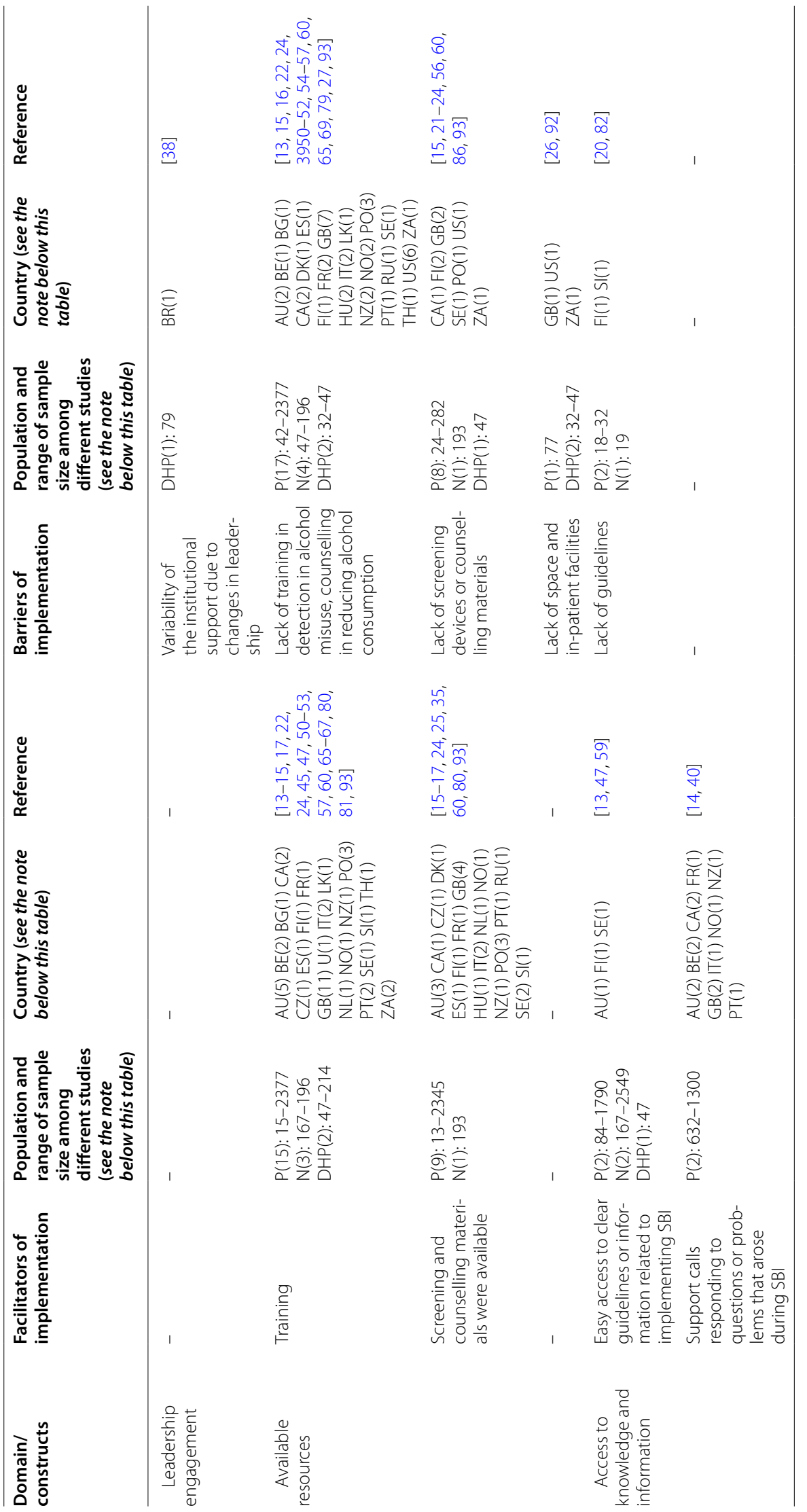




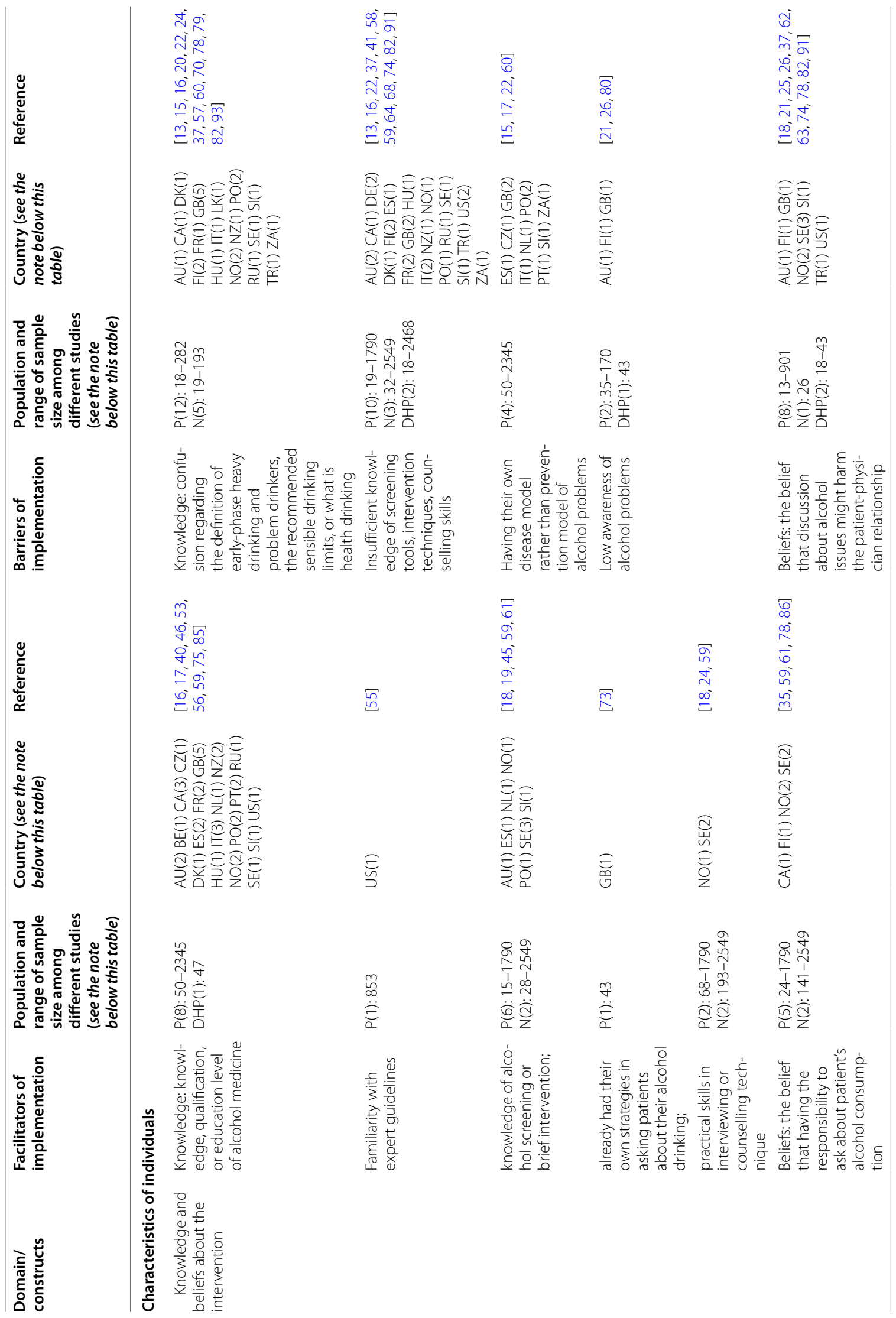




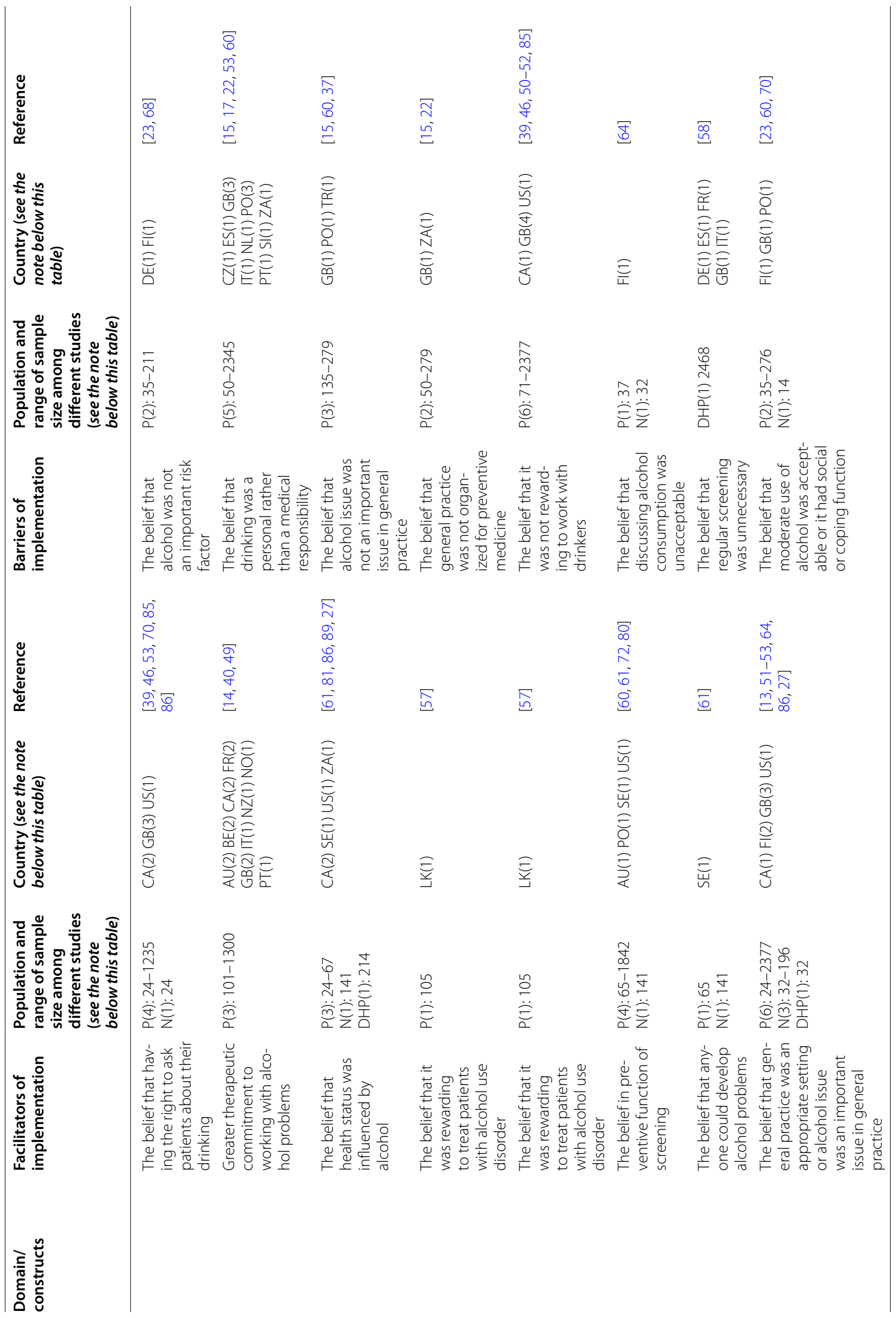




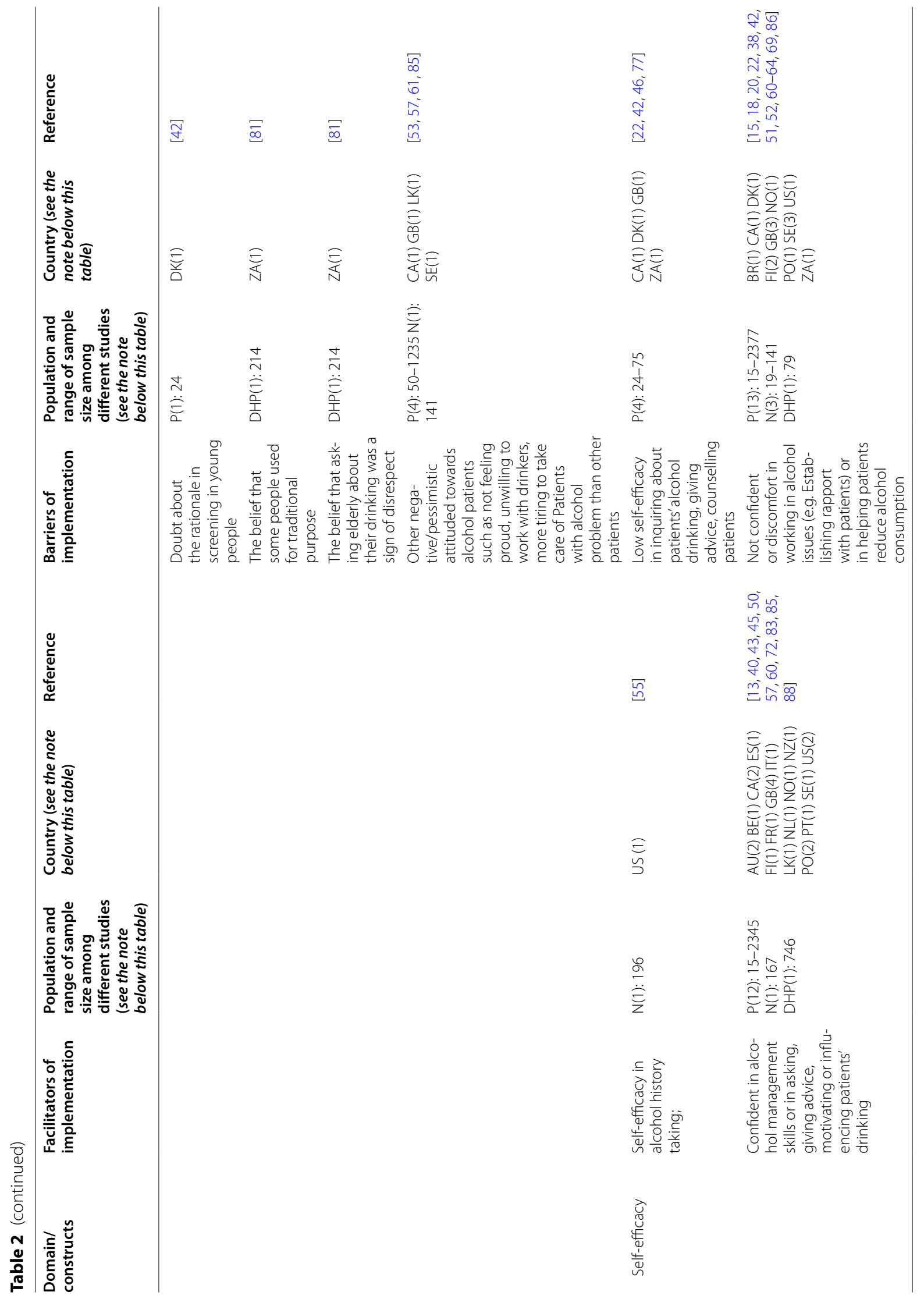




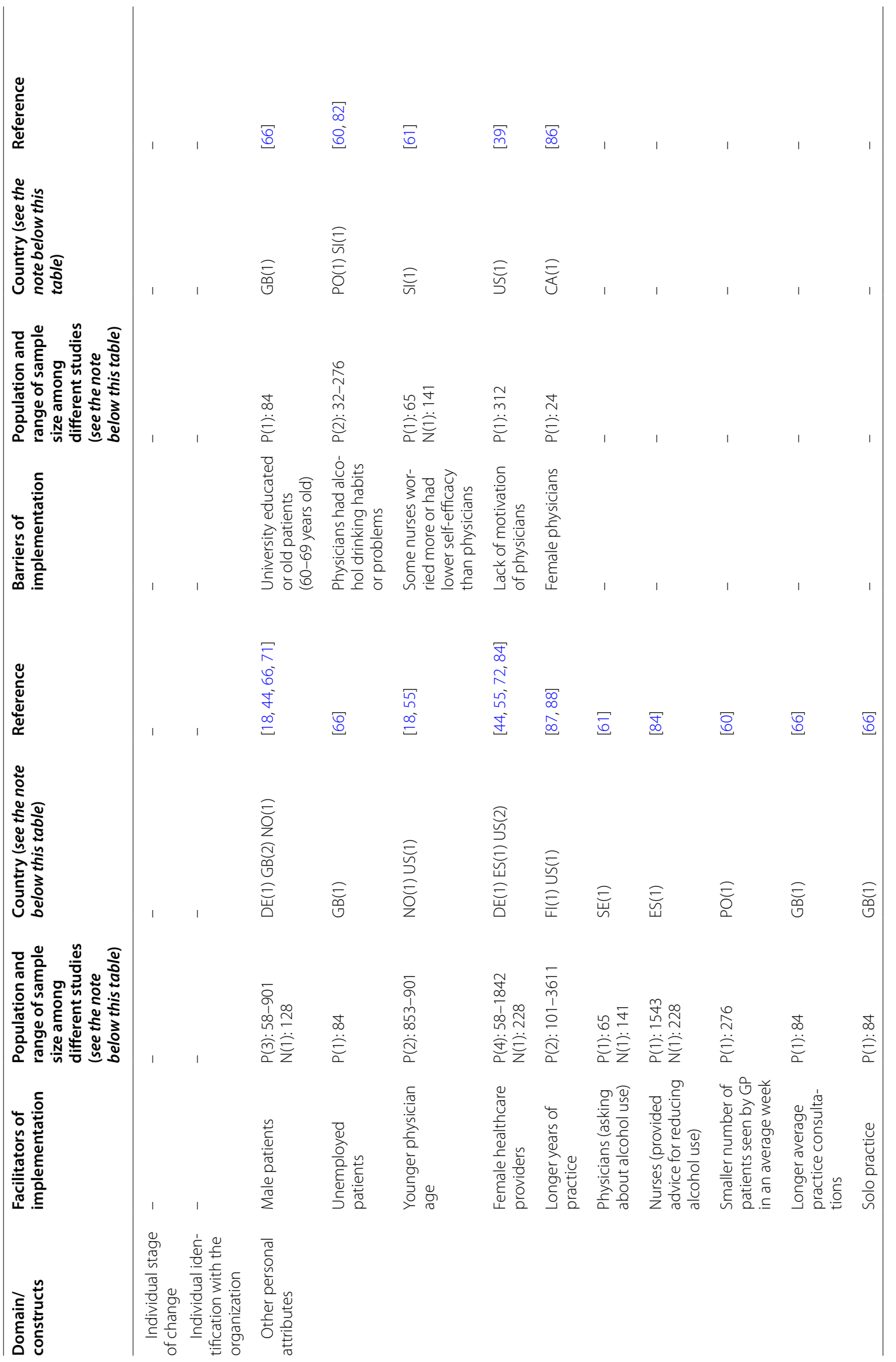




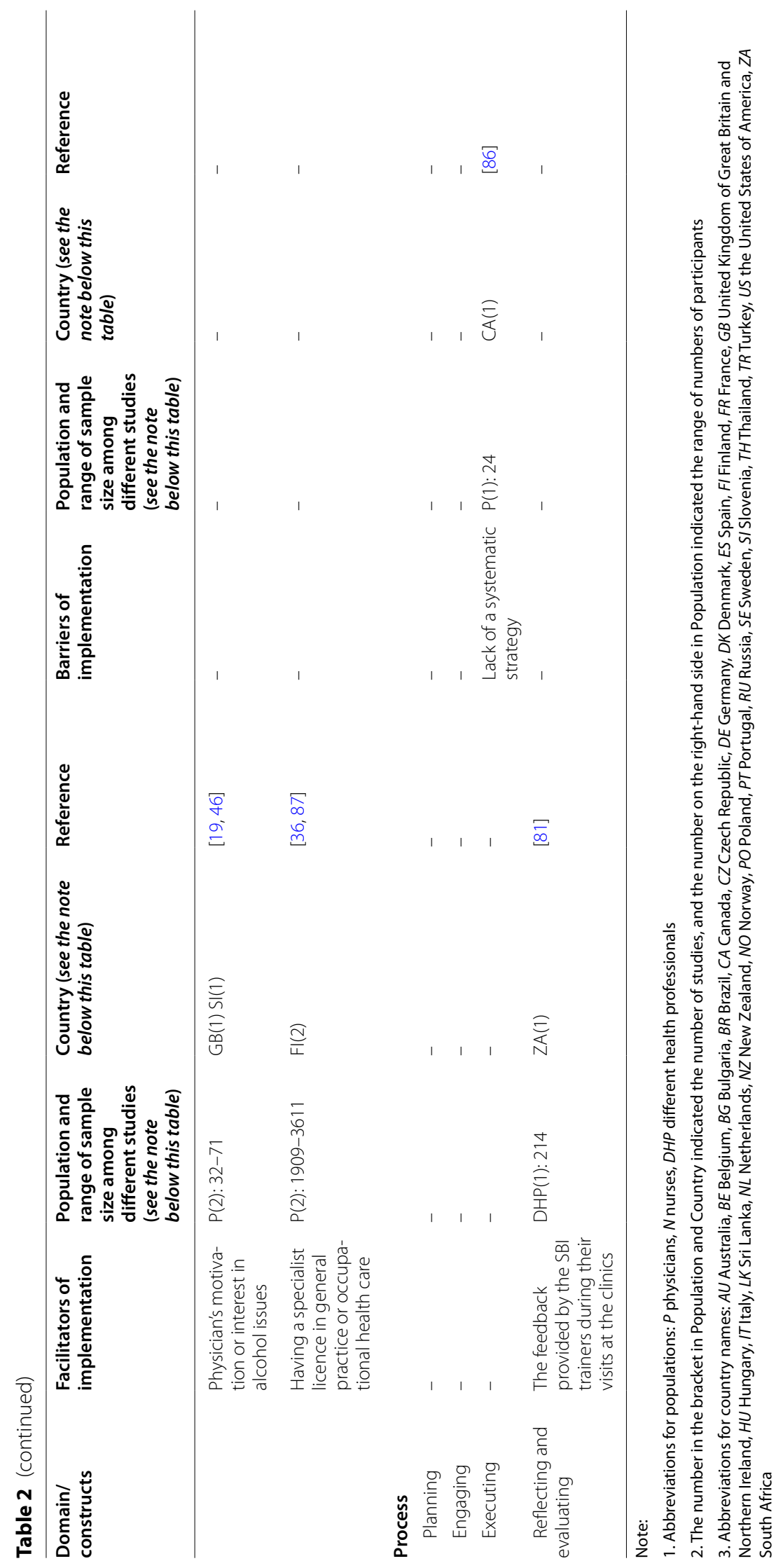


to be more complex or difficult to implement was associated with poorer SBI implementation among nurses and clinic managers in clinics in South Africa [81]. For design quality, in one qualitative study, different health professionals (e.g. social workers, psychologists, nurses) in Brazil agreed that simple SBI techniques could facilitate SBI implementation [38]. Numerous studies reported some barriers related to the cost associated with implementing SBI. For example, the workload increased by implementing SBI or lack of time were frequently reported among GPs, nurses, and other health professionals [15, $16,19-22,24-26,35,37,38,41,48,50-55,57-63,68,69$, $74-76,81-83,86,93]$ and about $36-76 \%$ of physicians or nurses thought that it would cause management or logistic problems [50-52, 56, 57].

Three constructs in this domain, intervention source, relative advantage, and trialability, were not studied.

\section{Outer setting}

For patient needs and resources, patients' active role as a facilitator was revealed in numerous studies $[13,15$, $16,21,47,51,59,60,62,66,71,80,83,93]$. For instance, about $52 \%$ of physicians, $50 \%$ of nurses, and $75 \%$ of health workers in Australia or Finland reported that patients' willingness to be asked about their drinking consumption or receive advice was a facilitator [13, 47]. About $76-80 \%$ of physicians in Poland and the UK suggested that patients' requests for health advice on alcohol consumption or self-motivation for seeking help were incentives for them to implement SBI $[15,16,51,60,83$, 93]. In addition, for two studies conducted in the UK, patients' risk status as measured by Alcohol Use Disorder Identification Test (AUDIT) by physicians was the most influential predictor for brief intervention [66, 71]. On the other hand, patients' negative reactions were cited as barriers to implementing SBI $[15,16,22-24,37,41,47-$ $49,54,55,60,61,68,70,76,82,91,27,93]$. For example, about $39-96 \%$ of physicians in Sweden, the UK, Poland, and South Africa reported that patients' refusal, unwillingness, low interests to take advice or receive help were barriers to implementing SBI $[15,16,22,47,48,54,55$, $60,61,82,27,93]$. Several studies revealed other barriers to implementing SBI in the USA, Finland, France, Germany, including patients' denial of alcohol misuse, dishonesty of alcohol consumption, and neglect of negative consequences caused by excessive alcohol consumption $[23,41,48,49,54,68,76,91]$.

For cosmopolitanism, available referral services were reported by physicians, nurses, and other health professionals as facilitators of implement SBI, such as the provision of addiction care and specialized treatment for alcohol problems $[15,18,19,24,46,50,52,57,59,60$, 72, $78,80,86,93]$. For instance, about $59-94 \%$ of physicians and $57-83 \% \%$ of nurses in Poland, Sweden, the UK, Sri Lanka, and the USA reported that access to local community alcohol teams, general support services (e.g. self-help or counselling), were facilitators of implementing SBI [15, $24,46,50,52,57,59,60,72,80,93]$. Regression analyses in one study conducted in Norway also showed that having places to refer patients to was significantly associated with physicians' screening or brief intervention activity [18]. On the contrary, the lack of referral services was also cited as a barrier to implementing SBI $[16,38$, $54-56,83,89,90,92,27]$. For instance, about $52-76 \% \%$ of physicians in Canada and the USA mentioned that wait-lists were long and treatment services were limited $[89,90]$. Moreover, univariate analyses showed that physicians in Sweden who infrequently addressed alcohol issues were more likely to be uncertain where to refer the patients [59].

Support from external policy was cited as an incentive to implement SBI $[15,16,19,60,93]$. About $65-82 \%$ of physicians in the UK and Poland suggested that implementation of SBI as part of a national strategy and more public health education campaigns make society more concerned about alcohol were enablers of SBI implementation $[15,60,93]$. However, lack of support from government policy was usually mentioned $[15,16,22,60,82]$. For instance, government policy that did not support preventive medicine was pointed out by $56-98 \%$ of physicians in South Africa, the UK, and Poland [15, 22, 60].

One construct, peer pressure, was not covered by previous studies.

\section{Inner setting}

For structural characteristics, teamwork or interprofessional cooperation in the delivery of SBI was suggested as a facilitator [38, 59, 74, 81]. In contrast, lack of staff, specialist support, or multidisciplinary team in primary care settings were cited as barriers [26, 41, 51, 92].

Concerning compatibility, doubt about the appropriateness of screening all patients and such activity causing interruptions of the natural course of consultations were reported by physicians in South Africa, Canada, and some European countries such as Norway, Slovenia, and the UK $[42,62,78,82,86]$.

High prioritization of alcohol issue was cited as an enabler by physicians, nurses, and clinic managers in South Africa, and the USA [74, 81] whereas a low rating of the importance of alcohol matter, competing priorities, or patients with multiple problems were reported as barriers by physicians, nurses, social workers, psychologists and other health professionals in Brazil, France, Germany, Italy, Spain, and the UK $[38,58,83]$. 
Two types of organizational rewards and incentives reported as facilitators, including provision of financial reimbursements/ salary improvements, and training for early alcohol intervention recognized for quality assurance credits [15-19, 60, 93]. About 35-84\% of physicians in Australia and some European countries considered that provision of financial reimbursements/salary improvements for carrying out early alcohol intervention, recognizing SBI training for continuing medical education (CME), or recognizing SBI for quality assurance credits were facilitators $[15,60,93]$. On the contrary, a lack of organizational incentives for SBI implementation was reported across countries $[15,16,22,26,60,69$, $82,92,93]$. For instance, about $31-90 \%$ of physicians in Poland, South Africa, the UK, and the USA reported that there was a lack of contractual incentives or the government health scheme did not reimburse their time spent on preventive medicine [15, 22, 60, 69, 93].

Regarding availability of resources, provision of SBI training was commonly discussed as a facilitator of implementation $[13-15,17,22,24,45,47,50-53,57,60$, $65-67,80,81,93]$. For example, about $42-90 \%$ of physicians, $90 \%$ of nurses in South Africa, Finland, the UK, Sweden reported provision of training in early alcohol intervention would encourage them to carry out screening or brief intervention [13, 15, 22, 24, 50-52, 57], and five studies conducted in 13 European, Asian, and American countries showed that receiving training in alcohol predicted more screening or intervention activities [14, 60, 65-67]. Nonetheless, lack of training was also frequently reported as a barrier in different studies $[13,15$, $16,22,24,39,48,50-52,54-57,60,65,69,79,27,93]$. For instance, about $32-98 \%$ of physicians and $75-90 \%$ of nurses in 19 Asian, American, African and European countries conducted by 12 studies reported that lack of training in detection in alcohol misuse, counselling in reducing alcohol consumption were the main barriers $[13,15,22,24,39,50-52,57,60,65,69]$. Apart from training, provision of screening questionnaires or counselling materials was also frequently cited as a facilitator $[15,17,24,25,60,80,93]$. For instance, about $51-86 \%$ of physicians and $74 \%$ of nurses in Australia, Sweden, the UK, and Poland reported that provision of screening devices or counselling materials encouraged them to do early alcohol intervention $[15,16,24,35,60,80,93]$. On the contrary, lack of materials was reported as a barrier in different studies [15, 21-24, 56, 60, 86, 93]. For example, about $41-98 \%$ of physicians and $56-63 \%$ of nurses in the UK, Sweden, Poland, and South Africa reported that lack of screening devices or counselling materials discouraged them to do early alcohol intervention $[15,22,24,60$, 93]. Furthermore, lack of other resources, such as space and in-patient facilities, were also reported as barriers by physicians, nurses, administrative staff, and practice managers in South Africa, the UK, and the USA [26, 92].

Regarding access to knowledge and information, easy access to clear guidelines related to implementing SBI was suggested [13, 47, 59]. Support calls responding to questions or problems that arose during SBI implementation were demonstrated to be effective in two multi-country studies $[14,40]$. However, a lack of simple guidelines was reported by physicians and nurses in Finland and Slovenia [20,82].

Four constructs in this domain were briefly discussed, i.e. culture, learning climate, goals and feedback, and leadership engagement. Regarding culture, one study conducted in Brazil reported that the organizational culture of alcohol use (e.g. often using alcohol during workrelated celebrations) in the primary care service of the Military Police would hamper treating problem drinkers [38]. For learning climate, more chances to try and observe SBI were reported as facilitators by nurses and clinic managers in South Africa [81]. A lack of understanding of the goals of SBI was mentioned in one study in the USA [27]. A decrease in institutional support due to changes in leadership was also reported in one study conducted in Brazil [38].

In this domain, two constructs, networks and communications, and tension for change, were not studied.

\section{Characteristics of individuals}

Possession of knowledge and positive beliefs about the intervention were reported as facilitators by 35 studies $[13,14,16-19,24,35,39,40,45,46,49,51-53,55-57$, $59-61,64,70,72,73,75,78,80,81,83,85,86,89,27]$. For example, familiarity with expert guidelines, perceived knowledge and skills of early alcohol intervention, and receiving higher levels of education training in alcohol were significantly associated with screening or intervention activity in one multi-country study and four others in Sweden, the USA, Spain, and Norway $[18,40,55,61,75]$. On the other hand, lack of knowledge, skills, or low awareness of alcohol problems were cited as barriers by 25 studies [13, 15, 16, 20-22, 24, $26,35,37,41,57-60,64,68,70,74,78-80,82,91,93]$. For example, about $30-70 \%$ of physicians or $39-65 \%$ of nurses reported that they did not know how to identify problem drinkers or how to define heavy drinking $[13,15,16,22,24,57,60,93]$. About $67-86 \%$ of physicians or $74-89 \%$ of nurses reported that they had insufficient knowledge about screening tools or counselling techniques [13, 16, 22, 41, 58]. For positive beliefs, screening or brief intervention activity was significantly associated with the belief of the importance of prevention or early alcohol intervention or having greater therapeutic commitment in working with alcohol 
problems in Sweden, the USA, France, and two multicountry studies [14, 40, 49, 61, 72]. However, many negative beliefs were also reported $[15,17,18,21-23$, $25,26,39,42,46,50-53,57,58,60-64,68,70,73,74$, $76,78,80-82,85,91]$. The most common one was the belief that discussion about alcohol issues might harm the patient-physician relationship $[18,21,25,26,37$, $62,63,74,78,82,91]$. Other negative beliefs included treating problem drinkers was not rewarding, alcohol was not an important risk factor, preventive health should be the patients' responsibility, and moderate use of alcohol was acceptable [15, 17, 22, 23, 39, 45, 49-52, $59,71,86]$.

Having high self-efficacy as an enabler was reported in different studies $[13,40,43,45,50,55,57,60,72,83$, $85,88]$. For instance, studies conducted in the USA, Poland, and one multi-country study showed that having high self-efficacy in alcohol history taking or alcohol management skills in helping reduce patients' alcohol consumption was associated with a higher number of interventions $[40,55,60,72,88]$. About $37-75 \%$ of physicians and $63 \%$ of nurses in the UK, Finland, or Sri Lanka reported that they were confident in asking, motivating, or influencing patients' drinking $[13,50,52]$. However, low self-efficacy in inquiring about patients' alcohol drinking, giving advice, or working in problem drinking in physicians or nurses were frequently reported $[18,22,38,42,46,51,52,60$, $61,69,77,86]$. About $32-65 \%$ of physicians or $31-65 \%$ of nurses in the UK, South Africa, Sweden, Finland, or the USA reported that they did not feel confident in working with problem drinkers, counselling skills, and helping the patients to reduce drinking $[15,22,46,51$, $52,60,61,64,69,77]$.

For other personal attributes, many demographic characteristics were found to be positively associated with SBI implementation. These personal characteristics included male patients $[18,44,66,71]$, younger physician age [18, 55], smaller number of patients seen by GPs in an average week [60], GPs having longer average practice consultations [66], GPs in solo practice [66]. In contrast, other personal characteristics were found to be barriers, such as old patients aged 60-69 years [66], physicians having alcohol drinking habits or problems [60, 82], some nurses worrying more or having lower self-efficacy than physicians [61]. Nevertheless, there were mixed results that some studies showed that female healthcare provider was a facilitator $[44,55,72,84]$, whilst it was considered a barrier in one study [86].

In this domain, two constructs, i.e. individual stage of change, and individual identification with the organization were not covered by previous studies.

\section{Process}

There is a lack of studies in this domain. For executing, physicians reported that there was a lack of a systematic strategy in the clinic in one study conducted in Canada [86]. For reflecting and evaluating, the feedback provided by the SBI trainers during their visits at the clinics was found to be helpful in one study conducted in South Africa [81].

Two constructs, planning and engaging, had not been studied.

\section{Facilitators and barriers not covered by the CFIR}

Facilitators that were not covered by the CFIR included medical documentation of patients' alcohol drinking, reminders for providers to do SBI, and reminders for patients about their medical condition. Barriers that were not covered by the CFIR included stigma-related issues, conflicting messages in the society that drinking alcohol was acceptable and even beneficial to health, alcohol counselling involving family and wider social effects, and providers' struggles in prevention versus treatment.

\section{Discussion}

In this systematic review, we sought to identify facilitators and barriers of SBI implemented by health professionals in primary care settings. We used the CFIR framework to analyse and summarize the facilitators and barriers.

We found that the practice rate of SBI was low in most countries on a regular basis. Among these countries, Finland, England, and France have participated in the WHO Phase IV implementation project (World Health Organization Collaborative Project on Identification and Management of Alcohol-Related Problems in Primary Health Care) [94]. Although the practice rate has increased since the commencement of this project, e.g. Finland [87], their practice rate is still below the satisfactory level. This may be due to social contextual factors. For instance, in Finland, alcohol problems used to be handled mostly by social welfare authorities and the police, and the disease model was adopted only later [21]. For future studies, researchers should investigate the specific contextual facilitators and barriers, and devise targeting strategies to help health professionals improve the practice of SBI in primary care settings. Nonetheless, the analysis of the practice of SBI was not the main aim of this review. Future work on the methodology of searching for articles specifically studying the current practice of SBI is recommended and a separate review and in-depth analysis will bring a more thorough discussion in this area.

The most common facilitators were knowledge and positive beliefs about SBI (characteristics of the individuals) and available resources (inner setting), whilst the 
most common barriers were cost related to implementing SBI (intervention characteristics), negative beliefs and the lack of knowledge (characteristics of the individuals), and the lack of self-efficacy (characteristics of the individuals). Notably, knowledge or lack of knowledge was cited as the most common facilitator or barrier. Knowledge as a facilitator contains several aspects, such as education on how alcohol influences health, familiarity with screening instruments, and counselling or intervention skills $[24,59,85]$. On the other hand, health professionals expressed difficulty in defining what is healthy drinking in different studies $[13,20,78,82]$. It was argued that many primary healthcare professionals still seemed to have the outdated dichotomous model of alcohol drinkers, i.e. those with alcohol dependence and moderate drinkers [20]. They should be informed that a more complex spectrum dividing alcohol problems into more detailed subgroups has been suggested, such as hazardous and harmful drinking in addition to alcohol dependence [20]. Training was the most common facilitator in the construct-available resources. Training is important for health professionals to acquire knowledge and practice skills required to perform screening and brief intervention. Under the construct cost, time cost appeared to be a prominent barrier. In most primary care settings, most physicians and nurses have to carry out a predetermined number of consultations, tasks, and assessments per day. They have limited time for each patient. They need to set priorities for screening conditions that they have tools and knowledge, or based on patients' requests $[21,59]$. Lack of self-efficacy is another important barrier. One of the main reasons may be the lack of guidelines about what they should do to alcohol drinkers [20, 82]. Allowing the professionals to apply simple guidelines creatively and select what was the most appropriate for their patients was related to higher self-efficacy $[20,46]$.

Most of the factors of SBI implementation identified in this systematic review are modifiable. There are a host of implementation strategies developed by implementation researchers for modifying factors to implement an intervention. For instance, Expert Recommendations for Implementing Change (ERIC) comprises a list of 73 implementation strategies [95-97]. The CFIR-ERIC Matching tool was developed which provides a list of implementation strategies to consider based on the CFIR-based barriers/facilitators [98, 99]. For instance, if the barrier, lack of self-efficacy, is selected, strategies such as conducting ongoing training, making training dynamic, providing ongoing consultations will be provided. For another example, if adaptability is selected, strategies such as conducting local needs assessment, identifying early adopters, and making tailoring strategies will be provided.
Moreover, when looking at how factors were studied according to the constructs in the CFIR framework, we observed that factors related to the inner setting and characteristics of individuals were extensively studied whilst the process received the least attention. Constructs in the inner setting and characteristics of individuals mainly focus on the assets of the organization and individuals, respectively. Researchers have put lots of effort into studying how the assets, such as available resources, knowledge, and training, affected the implementation of alcohol screening and brief intervention. Nonetheless, the role of the dynamic process of implementing SBI is generally neglected in previous studies, such as the process of planning, how different types of leaders engage in the implementation, as well as how to execute and evaluate the implementation process. It is conceivable that the consistently low uptake rate of SBI might be due to the lack of understanding of factors related to the implementation process. Therefore, future studies should examine the execution and processes of the SBI implementation.

To our knowledge, the CFIR was used by one systematic review to synthesize factors of implementing enhanced recovery pathways [100]. Similar to our findings, that systematic review suggested that more effort should be put into the implementation process in future studies. This conveys a message that the neglect of the implementation process may be one of the main reasons for the low uptake rate of many evidence-based practices in real settings. Therefore, using the CFIR to do systematic reviews of facilitators and barriers can help us gain a thorough understanding of implementation research .

There are three limitations in this systematic review. Firstly, we could not investigate whether there is a difference in facilitators or barriers between different types of health professionals, such as physicians and nurses, due to a relatively small number of studies involving nurses in this review. Secondly, different health systems or settings might induce different facilitators or barriers. Nevertheless, there is not enough information in the studies for stratification into different health systems or to the public or private sector. Since administration, culture, and management might be very different in different systems or sectors, it is possible that factors affecting the implementation of SBI might also be different. Thirdly, although the CFIR is comprehensive, it might not be able to cover some facilitators/barriers (e.g. stigma).

\section{Conclusions}

Most literature focused on various kinds of available assets to implement SBI. To promote the spread of SBI implementation, more high-quality studies on the implementation process are needed. This systematic review could serve as a reference framework for health authorities to devise 
strategies for improving the implementation of SBI in primary care settings.

\section{Abbreviations \\ AUDIT: Alcohol Use Disorder Identification Test; CFIR: Consolidated Framework for Implementation Research; CME: Continuing medical education; ERIC: Expert Recommendations for Implementing Change; GP: General practitioner; MMAT: Mixed-Method Appraisal Tool; RCT: Randomized controlled trial; SBI: Alcohol screening and brief intervention; WHO: World Health Organization.}

\section{Supplementary Information}

The online version contains supplementary material available at https://doi. org/10.1186/s13012-021-01170-8.

\section{Additional file 1. \\ Additional file 2. \\ Additional file 3.}

\section{Acknowledgments}

Not applicable.

\section{Authors' contributions}

Conceptualization: PSFC, ZW, EKY; Review methodology: PSFC, ZW, EKY, YF, MCSW, JH; Search strategies: PSFC, ZW with review by FY, MCSW, JH; Eligibility criteria: PSFC, ZW, EKY, YF, MCSW, JH; Article screening: PSFC, ZW, FY; Pilot extraction: PSFC, ZW, FY; Data extraction: PSFC, FY; Framework selection: PSFC, ZW, EKY. Writing-original draft preparation: PSFC, ZW, FY. Writing-review and editing: PSFC, ZW, EKY, YF, MCSW, JH. All authors read and approved the final manuscript.

\section{Funding}

(1) Direct Grant for research, the Chinese University of Hong Kong (Ref\#: 2019.23); (2) The Centre for Health Systems and Policy Research is funded by the Tung Foundation.

\section{Availability of data and materials}

All data generated or analysed during this study are included in this article (and its supplementary information files).

\section{Declarations}

Ethics approval and consent to participate Not applicable.

\section{Consent for publication}

Not applicable.

\section{Competing interests}

The authors declare that they have no competing interests.

\section{Author details}

1 JC School of Public Health and Primary Care, Faculty of Medicine, The Chinese University of Hong Kong, Hong Kong, China. ${ }^{2}$ Department of Early Childhood Education, The Education University of Hong Kong, Hong Kong, China. ${ }^{3}$ Center for Health Systems and Policy Research, JC School of Public Health and Primary Care, Faculty of Medicine, The Chinese University of Hong Kong, Hong Kong, China. ${ }^{4}$ Room 508, School of Public Health, Prince of Wales Hospital, Shatin, N.T., Hong Kong, China.

Received: 8 July 2021 Accepted: 29 October 2021 Published online: 20 November 2021

\section{References}

1. World Health Organization. Facesheet: alcohol 2018. Available from: https://www.who.int/news-room/fact-sheets/detail/alcohol. Accessed on 18 Sept 2020.

2. World Health Organization. Global status report on noncommunicable diseases 2014. Geneva: World Health Organization; 2014. Available at: https://www.who.int/nmh/publications/ncd-status-report-2014/en/. Accessed on 18 Sept 2020

3. World Health Organization. Screening and brief intervention for alcohol problems in primary health care. Available at: https://www.who.int/ substance_abuse/activities/sbi/en/. Accessed on 18 Sept 2020.

4. Anderson P, O'Donnell A, Kaner E. Managing alcohol use disorder in primary health care. Curr Psychiatry Rep. 2017;19(11):79.

5. Thomas B, Higgins-Biddle JC. Brief intervention for hazardous and harmful drinking (AUDIT): a manual for use in primary care. 2001. Available at: https://www.who.int/substance_abuse/publications/audit_sbi/ en/. Accessed on 18 Sept 2020.

6. Kaner EF, Beyer FR, Muirhead C, Campbell F, Pienaar ED, Bertholet N, et al. Effectiveness of brief alcohol interventions in primary care populations. The Cochrane Database Syst Rev. 2018:2:CD004148.

7. Moyer VA, Preventive Services Task F. Screening and behavioral counseling interventions in primary care to reduce alcohol misuse: U.S. preventive services task force recommendation statement. Ann Intern Med. 2013;159(3):210-8.

8. National Institute for Health and Clinical Excellence (NICE). Alcohol-usedisorders: diagnosis, assessment and management of harmful drinking and alcohol dependence. London: National Institute for Health and Clinical Excellence (NICE); 2011.

9. Royal Australian College of General Practitioners (RACGP). Smoking Nutrition, Alcohol and Physical Activity (SNAP) — a population health guide to behavioural risk factors in general practice, 2nd edition. East Melbourne: Royal Australian College of General Practitioners; 2015.

10. Colom J, Scafato E, Segura L, Gandin C, Struzzo P. Brief interventions implementation on alcohol from the European health systems perspective. Front Psychiatry. 2014:5:161.

11. Rehm J, Prieto JA, Beier M, Duhot D, Rossi A, Schulte B, et al. The role of alcohol in the management of hypertension in patients in European primary health care practices - a survey in the largest European Union countries. BMC Fam Pract. 2016;17(1):130.

12. Manthey J, Probst $C$, Hanschmidt F, Rehm J. Identification of smokers, drinkers and risky drinkers by general practitioners. Drug Alcohol Depend. 2015:154:93-9.

13. Aalto M, Pekuri P, Seppa K. Primary health care nurses' and physicians' attitudes, knowledge and beliefs regarding brief intervention for heavy drinkers. Addiction. 2001;96(2):305-11.

14. Anderson P, Kaner E, Wutzke S, Funk M, Heather N, Wensing M, et al. Attitudes and managing alcohol problems in general practice: an interaction analysis based on findings from a WHO collaborative study. Alcohol Alcohol. 2004;39(4):351-6.

15. Kaner EFS, Heather N, McAvoy BR, Lock CA, Gilvarry E. Intervention for excessive alcohol consumption in primary health care: attitudes and practices of English general practitioners. Alcohol Alcohol. 1999:34(4):559-66.

16. McAvoy BRDR, Jalleh G, Saunders JB, Wutzke SE, Lee N, et al. General Practitioners, Prevention and Alcohol - a powerful cocktail? Facilitators and inhibitors of practising preventive medicine in general and early intervention for alcohol in particular: a 12-nation key informant and general practitioner study. Drugs: Educ Prevent Pol. 2001;8(2):103-17.

17. Anderson P, Wojnar M, Jakubczyk A, Gual A, Segura L, Sovinova H, et al. Managing alcohol problems in general practice in Europe: results from the European ODHIN survey of general practitioners. Alcohol Alcohol. 2014:49(5):531-9.

18. Nygaard P, Paschall MJ, Aasland OG, Lund KE. Use and Barriers to Use of Screening and Brief Interventions for Alcohol Problems Among Norwegian General Practitioners. Alcohol Alcohol. 2010;45(2):207-12.

19. Kersnik J, Susic TP, Kolsek M, Svab I. What may stimulate general practitioners to undertake screening and brief intervention for excess alcohol consumption in Slovenia? A Focus Group Study. J Int Med Res 2009;37(5):1561-9. 
20. Aalto M, Pekuri P, Seppa K. Obstacles to carrying out brief intervention for heavy drinkers in primary health care: a focus group study. Drug Alcohol Rev. 2003;22(2):169-73.

21. Aira M, Kauhanen J, Larivaara P, Rautio P. Factors influencing inquiry about patients' alcohol consumption by primary health care physicians: qualitative semi-structured interview study. Fam Pract. 2003;20(3):270-5.

22. Koopman FA, Parry CDH, Myers B, Reagon G. Addressing alcohol problems in primary care settings: A study of general medical practitioners in Cape Town, South Africa. Scand J Public Healt. 2008;36(3):298-302.

23. Aira M, Kauhanen J, Larivaara P, Rautio P. Differences in brief interventions on excessive drinking and smoking by primary care physicians: qualitative study. Prev Med. 2004;38(4):473-8.

24. Geirsson M, Bendtsen P, Spak F. Attitudes of Swedish general practitioners and nurses to working with lifestyle change, with special reference to alcohol consumption. Alcohol Alcohol. 2005;40(5):388-93.

25. Arborelius ETK. Why is it so difficult for general practitioners to discuss alcohol with patients? Fam Pract. 1995;12(4):419-22.

26. Hutchings D, Cassidy P, Dallolio E, Pearson P, Heather N, Kaner E. Implementing screening and brief alcohol interventions in primary care: views from both sides of the consultation. Prim Health Care Res Dev. 2006:7(3):221-9.

27. Williams EC, Achtmeyer CE, Young JP, Rittmueller SE, Ludman EJ, Lapham GT, et al. Local implementation of alcohol screening and brief intervention at five Veterans Health Administration primary care clinics: perspectives of clinical and administrative staff. J Subst Abus Treat. 2016;60:27-35

28. Johnson M, Jackson R, Guillaume L, Meier P, Goyder E. Barriers and facilitators to implementing screening and brief intervention for alcohol misuse: a systematic review of qualitative evidence. J Public Health (Oxf). 2011;33(3):412-21.

29. Derges J, Kidger J, Fox F, Campbell R, Kaner E, Hickman M. Alcohol screening and brief interventions for adults and young people in health and community-based settings: a qualitative systematic literature review. BMC Public Health. 2017;17(1):562.

30. Keith RE, Crosson JC, O'Malley AS, Cromp D, Taylor EF. Using the Consolidated Framework for Implementation Research (CFIR) to produce actionable findings: a rapid-cycle evaluation approach to improving implementation. Implement Sci. 2017;12:1-12.

31. Damschroder LJ, Aron DC, Keith RE, Kirsh SR, Alexander JA, Lowery JC. Fostering implementation of health services research findings into practice: a consolidated framework for advancing implementation science. Implement Sci. 2009;4:1-5.

32. Moher D, Shamseer L, Clarke M, Ghersi D, Liberati A, Petticrew M, et al. Preferred reporting items for systematic review and meta-analysis protocols (PRISMA-P) 2015 statement. Syst Rev. 2015;4:1.

33. McCambridge J, Cunningham JA. The early history of ideas on brief interventions for alcohol. Addiction. 2014;109(4):538-46.

34. Pace R, Pluye P, Bartlett G, Macaulay AC, Salsberg J, Jagosh J, et al. Testing the reliability and efficiency of the pilot Mixed Methods Appraisal Tool (MMAT) for systematic mixed studies review. Int J Nurs Stud. 2012;49(1):47-53.

35. Aalto M, Varre T, Pekuri P, Seppa K. The role of general practitioners' working style and brief alcohol intervention activity. Addiction. 2003;98(10):1447-51.

36. Aalto M, Hyvonen S, Seppa K. Do primary care physicians' own AUDIT scores predict their use of brief alcohol intervention? A cross-sectional survey. Drug Alcohol Depen. 2006;83(2):169-73.

37. Akvardar Y, Ucku R, Unal B, Gunay T, Akdede BB, Ergor G, et al. Pratisyen Hekimler Alkol Kullanim Sorunlari Olan Hastalari Taniyor ve Tedavi Ediyorlar Mi? Turk Psikiyatri Derg. 2010;21(1):5-13.

38. Amaral MB, Ronzani TM, Souza-Formigoni MLO. Process evaluation of the implementation of a screening and brief intervention program for alcohol risk in primary health care: an experience in Brazil. Drug Alcohol Rev. 2010;29(2):162-8.

39. Anderson P. Managing alcohol problems in general practice. Br Med J (Clin Res Ed). 1985;290(6485):1873-5

40. Anderson P, Kaner E, Wutzke S, Wensing M, Grol R, Heather N, et al. Attitudes and management of alcohol problems in general practice: descriptive analysis based on findings of a world health organization international collaborative survey. Alcohol Alcohol. 2003;38(6):597-601.

41. Barry KL, Blow FC, Willenbring M, McCormick R, Brockmann LM, Visnic S. Use of Alcohol screening and brief interventions in primary care settings: implementation and barriers. Subst Abus. 2004;25(1):27-36.

42. Beich A, Gannik D, Malterud K. Screening and brief intervention for excessive alcohol use: qualitative interview study of the experiences of general practitioners. Brit Med J. 2002;325(7369):870-2b.

43. Bendtsen PAP, Wojnar M, Newbury-Birch D, Müssener U, Colom J, et al. Professional's attitudes do not influence screening and brief interventions rates for hazardous and harmful drinkers: results from ODHIN study. Alcohol Alcohol. 2015;50(4):430-7.

44. Berner MM, Harter M, Kriston L, Lohmann M, Ruf D, Lorenz G, et al. Detection and management of alcohol use disorders in German primary care influenced by non-clinical factors. Alcohol Alcohol. 2007:42(4):308-16.

45. Brennan C, Newton M, Wood F, Schug SA, Allsop S, Browne AL. Training general practitioners in remote Western Australia in a method of screening and brief intervention for harmful alcohol use: a pilot study. Aust J Rural Health. 2013;21(2):72-9.

46. Clement $\mathrm{S}$. The identification of alcohol-related problems by generalpractitioners. Br J Addict. 1986:81(2):257-64.

47. Clifford A, Shakeshaft A. Evidence-based alcohol screening and brief intervention in Aboriginal Community Controlled Health Services: experiences of health-care providers. Drug Alcohol Rev. 2011;30(1):55-62.

48. Coloma-Carmona A, Carballo JL, Tirado-Gonzalez S. Barriers for identification and treatment of problem drinkers in primary care. Gac Sanit. 2017;31(2):95-9.

49. Costa M, Yaya I, Mora M, Marcellin F, Villotitch A, Berenger C, et al. Barriers and levers in screening and care for alcohol use disorders among French general practitioners: results from a computerassisted telephone interview-based survey. Alcohol Treat Q. 2019;37(2):207-24

50. Deehan A, Taylor C, Strang J. The general practitioner, the drug misuser, and the alcohol misuser: major differences in general practitioner activity, therapeutic commitment, and 'shared care' proposals. Br J Gen Pract. 1997:47(424):705-9.

51. Deehan A, Templeton L, Taylor C, Drummond C, Strang J. Low detection rates, negative attitudes and the failure to meet the "Health of the Nation" alcohol targets: findings from a national survey of GPs in England and Wales. Drug Alcohol Rev. 1998;17(3):249-58.

52. Deehan AME, Taylor C, Strang J. Who in the primary health care team can tackle alcohol misuse? J Subst Use. 1999;4(1):51-6.

53. Farmer RGN. General practitioners' management of problem drinkers - attitudes, knowledge and practice. Drugs Educ Prev Policy. 2001:8(2):119-29.

54. Ferguson LRR, Russo J. Barriers to identification and treatment of hazardous drinkers as assessed by urban/rural primary care doctors. J Addict Dis. 2003;22(2):79-90.

55. Friedmann PD, McCullough D, Chin MH, Saitz R. Screening and intervention for alcohol problems. A national survey of primary care physicians and psychiatrists. J Gen Intern Med. 2000;15(2):84-91.

56. Gordon AJ, Ettaro L, Rodriguez KL, Mocik J, Clark DB. Provider, patient, and family perspectives of adolescent alcohol use and treatment in rural settings. J Rural Health. 2011;27(1):81-90.

57. Gurugama NP, Seneviratne SL, Peiris DT, de Silva HJ. Detection and management of alcohol misuse by general practitioners. Ceylon Med J. 2003;48(4):122-4.

58. Hanschmidt F, Manthey J, Kraus L, Scafato E, Gual A, Grimm C, et al. Barriers to Alcohol Screening Among Hypertensive Patients and the Role of Stigma: Lessons for the Implementation of Screening and Brief Interventions in European Primary Care Settings (vol 52, pg 572, 2017). Alcohol Alcohol. 2017:52(5):579.

59. Holmqvist M, Bendtsen P, Spak F, Rommelsjo A, Geirsson M, Nilsen P. Asking patients about their drinking - a national survey among primary health care physicians and nurses in Sweden. Addict Behav. 2008:33(2):301-14.

60. Jakubczyk A, Michalska A, Szejko N, Wojnar M. Attitudes towards managing alcohol problems in general practice - ODHIN study results for Poland. Alkohol Narkom. 2015;28(2):91-102. 
61. Johansson K, Bendtsen P, Akerlind I. Early intervention for problem drinkers: Readiness to participate among general practitioners and nurses in Swedish primary health care. Alcohol Alcohol. 2002;37(1):38-42.

62. Johansson K, Bendtsen P, Akerlind I. Factors influencing GPs' decisions regarding screening for high alcohol consumption: a focus group study in Swedish primary care. Public Health. 2005;119(9):781-8.

63. Johansson K, Akerlind I, Bendtsen P. Under what circumstances are nurses willing to engage in brief alcohol interventions? A qualitative study from primary care in Sweden. Addict Behav. 2005;30(5):1049-53.

64. Kaariainen J, Sillanaukee P, Poutanen P, Seppa K. Opinions on alcohol-related issues among professionals in primary, occupational, and specialized health care. Alcohol Alcohol. 2001;36(2):141-6.

65. Kaner EF, Wutzke S, Saunders JB, Powell A, Morawski J, Bouix JC, et al. Impact of alcohol education and training on general practitioners' diagnostic and management skills: findings from a World Health Organization collaborative study. J Stud Alcohol. 2001;62(5):621-7.

66. Kaner EFS, Heather N, Brodie J, Lock CA, McAvoy BR. Patient and practitioner characteristics predict brief alcohol intervention in primary care. Brit J Gen Pract. 2001;51(471):822-7.

67. Kaner E, Lock C, Heather N, McNamee P, Bond S. Promoting brief alcohol intervention by nurses in primary care: a cluster randomised controlled trial. Patient Educ Couns. 2003;51(3):277-84

68. Kraus L, Schulte B, Manthey J, Rehm J. Alcohol screening and alcohol interventions among patients with hypertension in primary health care: an empirical survey of German general practitioners. Addict Res Theory. 2017;25(4):285-92

69. Le KB, Johnson JA, Seale JP, Woodall H, Clark DC, Parish DC, et al. Primary care residents lack comfort and experience with alcohol screening and brief intervention: a multi-site survey. J Gen Intern Med. 2015;30(6):790-6.

70. Lock CA, Kaner E, Lamont S, Bond S. A qualitative study of nurses' attitudes and practices regarding brief alcohol intervention in primary health care. J Adv Nurs. 2002;39(4):333-42.

71. Lock CA, Kaner EFS. Implementation of brief alcohol interventions by nurses in primary care: do non-clinical factors influence practice? Fam Pract. 2004;21(3):270-5.

72. Marcell AV, Halpern-Felsher B, Coriell M, Millstein SG. Physicians'attitudes and beliefs concerning alcohol abuse prevention in adolescents. Am J Prev Med. 2002;22(1):49-55.

73. May C, Rapley T, Kaner E. Clinical reasoning, clinical trials and risky drinkers in everyday primary care: a qualitative study of British general practitioners. Addict Res Theory. 2006;14(4):387-97.

74. Miller PM, Stockdell R, Nemeth L, Feifer C, Jenkins RG, Nietert PJ, et al. Initial steps taken by nine primary care practices to implement alcohol screening guidelines with hypertensive patients: the AA-TRIP project. Subst Abus. 2006;27(1-2):61-70.

75. Miquel L, Lopez-Pelayo H, Nuno L, Arbesu JA, Zarco J, Manthey J, et al. Barriers to implement screening for alcohol consumption in Spanish hypertensive patients. Fam Pract. 2018;35(3):295-301.

76. Mules T, Taylor J, Price R, Walker L, Singh B, Newsam P, et al. Addressing patient alcohol use: a view from general practice. J Prim Health Care. 2012:4(3):217-22.

77. Nevin ACCP, Nulman I, Koren G, Einarson A. A survey of physicians knowledge regarding awareness of maternal alcohol use and the diagnosis of FAS. BMC Fam Pract. 2002;3(2):1-5.

78. Nygaard P, Aasland OG. Barriers to implementing screening and brief interventions in general practice: findings from a qualitative study in Norway. Alcohol Alcohol. 2011:46(1):52-60.

79. Owens LGI, Pirmohamed M. General practice nurses' knowledge of alcohol use and misuse: a questionnaire survey. Alcohol Alcohol. 2000;35(3):259-62.

80. Payne JEE, D'Antoine H, O'Leary C, Mahony A, Haan E. Health professionals'knowledge, practice and opinions about fetal alcohol syndrome and alcohol consumption in pregnancy. Aust N Z J Public Health. 2005;29(6):558-64.

81. Peltzer K, Matseke G, Azwihangwisi M, BaborT. Evaluation of alcohol screening and brief intervention in routine practice of primary care nurses in Vhembe district, South Africa. Croat Med J. 2008;49(3):392-401.

82. Poplas Susic T, Kersnik J, Kolsek M. Why do general practitioners not screen and intervene regarding alcohol consumption in Slovenia? A focus group study. Wien Klin Wochenschr. 2010;122(Suppl 2):68-73.
83. Rapley T, May C, Frances KE. Still a difficult business? Negotiating alcoholrelated problems in general practice consultations. Soc Sci Med. 2006;63(9):2418-28

84. Romero-RodriguezE, deTorres LAP, Leiva-Cepas F, Garcia JAF, Lopez SF, Muro $M M R$, et al. Knowledge, attitudes and preventive practices of primary health care professionals towards alcohol use: a national, cross-sectional study. PLos One. 2019;14(5):1-13.

85. Rush B, Bass M, Stewart M, McCracken E, Labreque M, Bondy S. Detecting, preventing, and managing patients'alcohol problems. Can Fam Phys. 1994;40:1557-66.

86. Rush BR, Powell LY, Crowe TG, Ellis K. Early intervention for alcohol-use family physicians motivations and perceived barriers. Can Med Assoc J. 1995;152(6):863-9.

87. Seppanen KK, Aalto M, Seppa K. Institutionalization of brief alcohol intervention in primary health care-the Finnish case. Alcohol Clin Exp Res. 2012;36(8):1456-61.

88. Sharp LV-HT. Physician attitudes regarding alcohol use screening in older adult patients. J Appl Gerontol. 2011;30(2):226-40.

89. Slaunwhite AK, Macdonald S. Alcohol, isolation, and access to treatment: family physician experiences of alcohol consumption and access to health care in rural British Columbia. J Rural Health. 2015;31(4):335-45.

90. Spandorfer JM, IsraelY,Turner BJ. Primary care physicians'views on screening and management of alcohol abuse - inconsistencies with national guidelines. J Fam Pract. 1999;48(11):899-902.

91. Tam CW, Zwar N, Markham R. Australian general practitioner perceptions of the detection and screening of at-risk drinking, and the role of the AUDITC: a qualitative study. BMC Fam Pract. 2013;14:121.

92. Van PMGC, Mollentze WF, Snyman JS, Joubert G. The role of private genera practitioners in the treatment of alcohol dependence in the Free State province. South African FamPract. 2013;55(6):561-6.

93. Wilson GB, Lock CA, Heather N, Cassidy P, Christie MM, Kaner EF. Intervention against excessive alcohol consumption in primary health care: a survey of GPs' attitudes and practices in England 10 years on. Alcohol Alcohol. 2011;46(5):570-7

94. World Health Organization. (2006). WHO Collaborative Project on Identification and Management of Alcohol-Related Problems in Primary Health Care : report on phase IV: development of country-wide strategies for implementing early identification and brief intervention in primary health care / edited by Nick Heather. World Health Organization. Available from: https://apps.who.int/iris/handle/10665/43519. Accessed 23 Apr 2021

95. Powell BJ, Waltz TJ, Chinman MJ, Damschroder L, Smith JL, Matthieu MM, et al. A refined compilation of implementation strategies: results from the Expert Recommendations for Implementing Change (ERIC) project. Implement Sci. 2015;10:21.

96. Waltz TJ, Powell BJ, Matthieu MM, Damschroder LJ, Chinman MJ, Smith JL, et al. Use of concept mapping to characterize relationships among implementation strategies and assess their feasibility and importance: results from the Expert Recommendations for Implementing Change (ERIC) study. Implement Sci. 2015;10:109.

97. Perry CK, Damschroder LJ, Hemler JR, Woodson TT, Ono SS, Cohen DJ. Specifying and comparing implementation strategies across seven large implementation interventions: a practical application of theory. Implement Sci. 2019;14(1):32.

98. Consolidated Framework for Implementation Research: Strategy design. Available from: https://cfirguide.org/choosing-strategies/. Accessed on 5 Sept 2021.

99. Waltz TJ, Powell BJ, Fernandez ME, Abadie B, Damschroder L.Choosing implementation strategies to address contextual barriers: diversity inrecommendations and future directions. Implement Sci. 2019;14(1):42.

100. Stone AB, Yuan CT, Rosen MA, Grant MC, Benishek LE, Hanahan E, et al. Barriers to and Facilitators of Implementing Enhanced Recovery Pathways Using an Implementation Framework A Systematic Review. Jama Surg. 2018;153(3):270-9.

\section{Publisher's Note}

Springer Nature remains neutral with regard to jurisdictional claims in published maps and institutional affiliations. 